\title{
Adsorption Of Methylene Blue from Aqueous Solution with Sulfuric Acid Activated Corn Cobs: Equilibrium, Kinetics, and Thermodynamics Assessment
}

\author{
Pinar Bozbeyoglu1 ${ }^{\text {DD }}$ Celal Duran ${ }^{2}$ Cemalettin Baltaci ${ }^{3}$ (D) Ali Gundogdu ${ }^{4}$ \\ ${ }^{1}$ Gumushane University, Department of Biotechnology, Gumushane, Turkey \\ ${ }^{2}$ Karadeniz Technical University, Department of Chemistry, Trabzon, Turkey \\ ${ }^{3}$ Gumushane University, Department of Food Engineering, Gumushane, Turkey \\ ${ }^{4}$ Karadeniz Technical University, Department of Pharmacy Services, Trabzon, Turkey
}

\section{ABSTRACT}

$\mathrm{T}$ hree adsorbents with different characteristics were produced in this study by activation of sulfuric acid with different concentrations, from corn (Zea mays L.) cobs, which is an agricultural waste by-product resulting from harvesting. After characterization by the parameters such as Boehm titration, determination of $\mathrm{pH}-\mathrm{pHpzc}$, and methylene blue iodine number, and IR analysis, their methylene blue adsorption potentials from aqueous medium were investigated based on equilibrium, kinetics, and thermodynamics evaluations. This study aims to examine the effects of relatively dilute and concentrated acids on the activation process and to gain an economic value to waste materials through the production of a new adsorbent. It was observed that the initial solution $\mathrm{pH}$ did not have a significant effect on the adsorption efficiency. The adsorption process reached the equilibrium at the end of the first 120 minutes, and the kinetic data fit the pseudo-second-order kinetic model. Langmuir adsorption capacity $(295.5 \mathrm{mg} / \mathrm{g})$ of the adsorbent produced by activating with 50\% sulfuric acid was found higher than those produced with $75 \%$ and $98 \%$ acids. An increase in ambient temperature effected the adsorption positively. As a result, in this study, very low-cost adsorbents were produced from the waste by-product corn cobs, and a new approach was proposed for cleaning wastewater containing dyestuffs.

Keywords:

Adsorption; Corn cobs; Methylene blue; Removal; Sulfuric acid activation
Article History:

Received: 2020/09/02

Accepted: 2020/og/17

Online: $2020 / 09 / 30$

Correspondence to: Ali Gundogdu, Karadeniz Technical University, Macka Vocational School, Pharmacy Services, 61750, Macka, Trabzon, TURKEY E-Mail:a.ramazan.gundogdu@gmail.com Phone: +904625123535

Fax:+90 4625123552

\section{INTRODUCTION}

$\mathrm{N}$ Tatural waters are getting more and more polluted due to the activities of many industry organizations such as juice, coffee, and cereal processing plants. The contamination of the water used for drinking and other purposes by partially treated or untreated discharges from chemical industries, petrochemical industries, oil refineries, oil spills, rolling steel mills, unrefined domestic sludge, and pesticide runoff threaten both human health and environmental health [1]. Dyestuffs, one of many different types of contaminants, are among the chemicals that pose this threat. Synthetic dyestuffs are widely used worldwide in textile staining processes. Synthetic dyestuff classes are the azo type, including reactive, disperse, and acid dyes. Azo dyes account for $65 \%$ of the total dye production in the world [2]. Today, biological treatment is the most widely used method to decompose dye waste. However, this process is not very successful in removing dyes effectively. For this reason, dyes are often found chemically unchanged in the waters of wastewater treatment plants; and they can both contaminate drinking water and cause potential aquatic toxicity by condensation in sludge.

In the textile industry, about $1 \mathrm{~m}^{3}(1000 \mathrm{~mL})$ of water is required for every 1 ton $(1000 \mathrm{~kg})$ of clothes to be stained. The discharge of wastes of these processes into rivers and lakes can have toxic effects on aquatic life. Color impedes the penetration of light into the water and thus impedes the growth of biota by retarding photosynthetic activity. It also chelates metal ions in the water, causing micro-toxicity for aquatic life [3]. It should be borne in mind that even $1.0 \mathrm{mg} / \mathrm{L}$ concentration of any dye in drinking water can impart a significant amount of color making it highly unsuitable for human consumption. Most of the dyes used in industrial applications are very stable against photo-degradation, biodegradation and oxidizing agents. Today, several physi- 
cal and chemical processes are used to treat wastewater. However, many of these processes are expensive and cannot be used effectively to treat a wide variety of dye effluents $[4,5]$.

Activated carbon-based industrial processes are the most widely used methodologies as they have excellent removal efficiency for dyes and of course many other types of contaminants, but the use of these processes is often limited due to the high cost of commercial activated carbons and high energy-process [6]. Therefore, it is inevitable to develop new adsorption-based technologies that can be a powerful alternative to activated carbon-based ones. Number of alternative methods are increasing day by day to reduce costs and also increase efficiency, or at least to compete with other methodologies. For this purpose, studies on lignocellulosic agricultural wastes or by-products are available in the literature. These agricultural wastes can be used inexpensively as a direct adsorbent or by converting into activated carbons or by activating with various agents to improve their adsorption capabilities. This type of agricultural waste by-products can be easily obtained from many industrial establishments, or farming peasants at very low costs.

Hundreds of agricultural-based waste by-products such as corn cob, barley straw [7], carrot waste [8], alder sawdust [9], rice husks, olive pomace, orange waste [10], Kiwicucumber-potato peel [11], sago waste [12], coffee husk [13], peanut shells [14], rice husk waste, coconut shell [15], hazelnut husk [16], and tea-industry waste [17] are used either directly or by converting into activated carbons to remove various pollutants from aqueous medium. In this way, very low cost and high-performance adsorbents can be obtained from these by-products with no economic value.

In this study, three different adsorbents were produced from corn cobs (CCs) by chemical activation using the different concentrations of sulfuric acid. CCs is a waste byproduct after processing of the maize plant (Zea Mays L.) cultivated in almost every region of Turkey as well as all over the world. In the 2018/2019 period, approximately 5.7 million tons of corn were produced in Turkey [18]. Significant amounts of waste CCs are released from these products. There is no document that these wastes are used in any area.

The potential of these adsorbents to remove methylene blue (MB), a basic cationic dyestuff, from aqueous solution was investigated in this study. MB is one of the most used dyestuffs in the medical field, but also in dyeing wool, wood, paper, silk and leather, painting, and ink dyes. However, MB may cause some harmful effects on human health. A person exposed to MB may experience heart palpitations, vomiting, shock, cyanosis, known as blue disease, jaundice, arm, and leg paralysis, and tissue gangrene [19-21]. MB is very sensitive to heat. When left at $110^{\circ} \mathrm{C}$ for 2 hours, it emits a bad odor and loses about $14 \%$ mass. Anhydrous MB is $94.5 \%$ pure and creates foam in aqueous solution [22]. Besides, MB, which has a maximum absorption wavelength of $668 \mathrm{~nm}$, is widely used as a model adsorbate to test the adsorption capacity of the relevant adsorbent or the degradation potential of any $\mathrm{TiO}_{2}$ film $[23,24]$. Also, one of the characterization steps of a newly produced adsorbent is of course determination of $\mathrm{MB}$ number as well as $\mathrm{I}_{2}$ number.

In a study in the literature, although it was reported that a new adsorbent was obtained from CCs by activating with concentrated sulfuric acid [25], three different adsorbents were obtained by using different concentrations of sulfuric acid in this study. Relatively dilute acids dissociate more than concentrated acids. Therefore, the adsorbent obtained by activating with relatively dilute acid is expected to have richer surface functional groups. The primary aim of this study is to prove that the adsorbents produced by changing the concentration of sulfuric acid used for activation of CCs have different adsorption capabilities and that dilute acids perform better than concentrated ones. In other words, this study aims to monitor the development and reorganization of adsorption sites on the adsorbent surface containing functional groups and to reveal the adsorption capabilities of the adsorbents produced by changing the concentration of the activation agent. Since we do not find such a study in the literature, we think that this work is original, and the novelty is high. New adsorbents have been produced from CCs, which are an agricultural waste by-product, at almost zero cost, thereby gaining an economic value for such a worthless material. Besides, we believe that this study is very valuable as it is expected that these adsorbents will contribute to the prevention of environmental water pollution.

\section{MATERIAL AND METHOD}

\section{Chemicals, Solutions and Matter-Materials Used}

All chemicals used in the experimental stages were of analytical purity and were purchased from Merck (Darmstadt, Germany). Ultra-pure water was used in all experiments. Methylene blue (MB) used as an adsorbate in adsorption tests is a basic cationic dye. Other known names of $\mathrm{MB}$, whose empirical Eq. and molar mass are $\mathrm{C}_{16} \mathrm{H}_{18} \mathrm{ClN}_{3} \mathrm{~S}$ and $319.85 \mathrm{~g} / \mathrm{mol}$, respectively, are methylthioninium chloride, CI 52015, and basic blue 9 [26]. Its molecular structure is shown in Fig. 1.

The appropriate amount of MB was weighed and dissolved in water, and its stock solution of $2500 \mathrm{mg} / \mathrm{L}$ was prepared. The six consecutive solutions of $50,100,250,500,750$ and $1000 \mathrm{mg} / \mathrm{L}$ were prepared from this stock solution by diluting. Capped PP Falcon tubes of 15 - and 50-mL volumes were used in the adsorption tests. 
A vacuum filtration system (Isolab, $\mathrm{GmbH}$ ) was used to separate the adsorbate molecules (MB) and adsorbent particles (CCs-SA) from each other. In this setup, the nitrocellulose membrane (Sartorius Stedim Biotech, France) with a pore size of $0.45 \mu \mathrm{m}$ was used as a filter paper.

\section{Devices Used}

In this study, $\mathrm{MB}$ concentrations were determined in a Unicam UV-2 model Spectrophotometer device. Adsorption tests were made with a mechanical shaker (Edmund Bühler $\mathrm{GmbH}$ ), pH adjustments were made with a Hanna pH-211 model benchtop pH meter (Hanna Inst., USA) and substance weighing was done with a BP1106 model analytical balance (Sartorius Stedim Biotech, France). The IR spectra of the adsorbents were obtained from a Perkin Elmer 1600 FT-IR spectrophotometer (4000-400 $\mathrm{cm}^{-1}$ ) device.

\section{Preparation of the Adsorbents:}

The corn cobs (CCs) were obtained from Akçaabat district of Trabzon province-Turkey. After separating the grains, the remaining CCs were dried in an oven at 105 ${ }^{\circ} \mathrm{C}$ for 24 hours and stored in a desiccator. The dried CCs wastes were used after being milled and sieved to a size of approximately $4 \mathrm{~mm}$.

$20 \mathrm{~g}$ of $\mathrm{CCs}$ were taken and $20 \mathrm{~g}$ of $\mathrm{H}_{2} \mathrm{SO}_{4}$ solutions of three different concentrations $(98 \%, 75 \%$ and $50 \%$ by weight) were added separately (mixing ratio 1:1). After mixing the mixtures thoroughly, they were kept in the oven at $200{ }^{\circ} \mathrm{C}$ for 24 hours. The activated adsorbents were first washed thoroughly with boiling distilled water to remove acid residues and then neutralized by treatment with a $1 \%$ $\mathrm{NaHCO}_{3}$ solution for 24 hours. After the adsorbents were filtered, they were washed again with ultrapure water and finally they were used after drying in the oven at $105{ }^{\circ} \mathrm{C}$ for 24 hours [27]. The three different adsorbents obtained were coded as $\mathrm{CCs}_{-} \mathrm{SA}_{50}, \mathrm{CCs}-\mathrm{SA}_{75}$, and CCs-SA ${ }_{98}$.

\section{Characterization of the Adsorbents:}

\section{Analysis of The Surface Acidic Functional Groups (SAFG) of The Adsorbents}

The surface acidic functional groups of the adsorbents are mainly examined in three groups as carboxylic, lactonic and phenolic. The amounts of these groups in mmol can be determined by Boehm Titration. With $0.05 \mathrm{~g}$ adsorbent, $0.1 \mathrm{~N} 50 \mathrm{~mL} \mathrm{NaOH}, \mathrm{NaHCO}_{3}$ and $\mathrm{Na}_{2} \mathrm{CO}_{3}$ solutions were treated separately for 24 hours. At the end of the process, after the samples were filtered through the cellulose nitrate membrane with pores $0.45 \mu \mathrm{m}$ in size, the filtrates were titrated with $0.1 \mathrm{~N} \mathrm{HCl}$ [28].

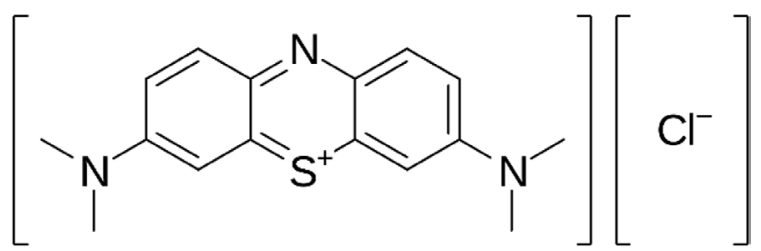

Figure 1. Molecular structure of methylene blue.

Total surface acidic groups (lactonic, phenolic and carboxylic) are all determined by $\mathrm{NaOH}$-neutralization. Lactonic and carboxylic groups are determined by $\mathrm{Na}_{2} \mathrm{CO}_{3}-$ neutralization, and only carboxylic groups by $\mathrm{NaHCO}_{3}-$ neutralization [29].

The amount of surface acidic functional groups in mmol is calculated by the following Eq. 1:

$$
S A F G=\frac{\left[N \times\left(\mathrm{T}_{\mathrm{b}}-\mathrm{T}\right) \times 2.5\right]}{m}
$$

where SAFG means surface acidic functional groups $(\mathrm{mmol} / \mathrm{g})$. $\mathrm{N}$ is the normality of the titrant solution $(\mathrm{HCl})$. $T_{\mathrm{b}}$ is the titrant consumption $(\mathrm{mL})$ for blank experiments. $T$ represents the titrant consumption $(\mathrm{mL})$ for the different solutions, and $\mathrm{m}$ is the amount of adsorbent $(\mathrm{g})$.

\section{pH and $\mathrm{pH}_{p z c}$ Values of The Adsorbents}

The $\mathrm{pH}$ values of the adsorbents were determined by measuring the filtrate with a $\mathrm{pH}$ meter after treating the 0.05 g adsorbent with $10 \mathrm{~mL}$ ultrapure water heated to boiling point for 24 hours [30].

The $\mathrm{pH}$ of an adsorbent at the neutral charge point $\left(\mathrm{pH}_{\mathrm{pzc}}, \mathrm{pH}\right.$ of point of zero charge) or at the isoelectric point means the $\mathrm{pH}$ value at the point where the net charge on the surface of adsorbent is zero. If $\mathrm{pH}>\mathrm{pH}_{\mathrm{pzc}}$, adsorption of cationic species on the adsorbent is more suitable. In the case of $\mathrm{pH}<\mathrm{pH}_{\mathrm{pzc}}$, on the contrary, adsorption of anionic species is more suitable. Knowing the $\mathrm{pH}_{\mathrm{pzc}}$ value, an appropriate value of the solution $\mathrm{pH}$ can be estimated for the adsorption of cationic or anionic species without the need for a wide $\mathrm{pH}$ scan. Below $\mathrm{pH}_{\mathrm{pzc}}$, the net charge on the surface of an adsorbent is positive and above it is negative.

For the determination of $\mathrm{pH}_{\mathrm{pzc}}$ values of the adsorbents, a series of $0.1 \mathrm{M} \mathrm{NaCl}$ solutions in which they initial $\mathrm{pH}$ values were adjusted between 2.0 and 10.0 with $0.1 \mathrm{M} \mathrm{NaOH}$ or $0.1 \mathrm{M} \mathrm{HNO}_{3}$ were treated with $0.1 \mathrm{~g}$ of the adsorbent for 24 hours. At the end of the process, after the adsorbent and solution were separated by filtration, the equilibrium $\mathrm{pH}$ values of the filtrates were measured with a $\mathrm{pH}$ meter. A graph was drawn by subtracting the equilibrium $\mathrm{pH}$ values from the initial $\mathrm{pH}$ values and placing them on the $\mathrm{y}$-axis $(\Delta \mathrm{pH})$ and the initial $\mathrm{pH}$ values on the $\mathrm{x}$-axis. The point where the graph cuts the $\mathrm{x}$-axis from the value where $y$ is zero was recorded as $\mathrm{pH}_{\mathrm{pzc}}[31,32]$. 


\section{Methylene blue and Iodine Numbers of The Adsorbents}

The methylene blue number $(\mathrm{MBn})$ is a measure of the ability of an adsorbent to adsorb large molecules. This test is one of the most important tests that characterize activated carbons. To find $\mathrm{MBn}$ in this study, $10 \mathrm{~mL}$ of $1000 \mathrm{mg} / \mathrm{L} \mathrm{MB}$ solution and $0.02 \mathrm{~g}$ of each adsorbent were treated for 12 hours. After the mixture was filtered through a $0.45 \mu \mathrm{m}$ nitrocellulose membrane, the $\mathrm{MB}$ concentration remaining without adsorbed in the filtrate was determined by UV-Vis spectrophotometer. Then, the quantity of $\mathrm{MB}$ adsorbed per gram adsorbent $(\mathrm{mg} / \mathrm{g})$ was calculated with the help of Eq. 2 below [22].

$$
M B_{n}=\frac{\left(C_{o}-C_{e}\right)}{m} x V
$$

where $\mathrm{MBn}$, it means methylene blue number. $\mathrm{C}_{\mathrm{o}}$ and $\mathrm{C}_{\mathrm{e}}$ are the initial and equilibrium methylene blue concentrations $(\mathrm{mg} / \mathrm{L})$, respectively. $\mathrm{V}$ is the solution volume $(\mathrm{mL})$ and $\mathrm{m}$ is the adsorbent mass ( $\mathrm{g}$ ).

Iodine $\left(\mathrm{I}_{2}\right)$ is a much smaller molecule compared to $\mathrm{MB}$. The high number of $\mathrm{I}_{2}$ gives important information about the adsorbents' ability to adsorb small atoms or molecules such as metal ions [33]. The increase in surface area, porosity and active groups is a factor that increases $\mathrm{I}_{2}$ adsorption. The following procedure was used to determine the $I_{2}$ number of the adsorbents:

$0.2 \mathrm{~g}$ of the adsorbent was weighed into a $50 \mathrm{~mL}$ pp Falcon tube. $40 \mathrm{~mL} 0.1 \mathrm{~N}$ standard iodine solution $\left(12.7 \mathrm{~g} \mathrm{I}_{2}\right.$ and $19.1 \mathrm{~g}$ KI dissolved in $1 \mathrm{~L}$ water in total) was added and carefully shaken for $30 \pm 1 \mathrm{~h}$. After the mixture was filtered, the amount of unadsorbed iodine in the solution was titrated with a $0.1 \mathrm{~N}$ standard sodium thiosulfate solution. A new $40 \mathrm{~mL}$ iodine solution was taken, and the consumption was recorded as a blank by titrating with $0.1 \mathrm{~N}$ standard sodium thiosulfate solution without adding the adsorbent and shaking [34]. The $\mathrm{I}_{2}$ numbers of the adsorbents were calculated by the following equations (Eq.s 3, 4 and 5):

$$
\begin{aligned}
& I_{2} \text { number }(m g / g)=F x C \\
& F=\frac{126.93 x N_{I_{2}} x V_{f}}{m x V_{k}} \\
& C=V_{k}-V_{t}
\end{aligned}
$$

where $\mathrm{N}_{2}$ refers to the normality of the standard iodine solution. Vf and Vk mean the filtrate volume $(\mathrm{mL})$ and the standard thiosulfate consumption $(\mathrm{mL})$ for the samples, respectively. $\mathrm{m}$ is the adsorbent mass $(\mathrm{g})$.

\section{IR analysis of the adsorbents}

Infrared spectrometry (IR) is a frequently used method to illuminate the chemical structures and surface groups of various adsorbents. In this study, IR spectra were taken by FT-IR (Fourier Transform-Infra-Red) spectrometry for CCs, CCs-SA ${ }_{50}, \mathrm{MB}$ loaded CCs-SA 50 and MB, and the changes occurring before and after adsorption were examined.

Approximately $10 \mathrm{mg}$ of the well-dried adsorbents were taken into the chamber of the device and IR spectra were taken directly.

\section{Adsorption Tests}

In this study, three different adsorbents were obtained by activating the corn cob with sulfuric acid at different concentrations. The adsorption performance of a total of four adsorbents from aqueous solution together with the original corn cob was tested. As the adsorbate, methylene blue (MB), a basic cationic dye, was used to represent the total dyes in the adsorption studies.

$0.050 \mathrm{~g}$ of the adsorbents were weighed and mixed with $10 \mathrm{~mL}$ of 6 different MB solutions between 50-1000 mg/L and treated separately until equilibrium was reached. Then, adsorbent particles and adsorbate molecules were separated from each other with the help of a vacuum filtration device. The concentrations of MB remaining in the filtrate were determined at $668 \mathrm{~nm}$ in a UV-Vis spectrophotometer in the $\mathrm{mg} / \mathrm{L}$ concentration unit. The results were then converted to $\mathrm{mg} / \mathrm{g}$ by Eq. 6 and \% by Eq. 7 .

$$
\begin{gathered}
Q_{e}(m g / g)=\frac{C_{o}-C_{e}}{m} x V \\
Q e(\%)=\frac{C o-C e}{C o} x 100
\end{gathered}
$$

where $\mathrm{Q}_{\mathrm{e}}(\mathrm{mg} / \mathrm{g})$ and $\mathrm{Q}_{\mathrm{e}}(\%)$ mean the amount of $\mathrm{MB}$ molecules adsorbed on the adsorbent at equilibrium. $\mathrm{C}_{\mathrm{o}}$ and Ce represent the initial and equilibrium $\mathrm{MB}$ concentrations (mg/L), respectively. $\mathrm{m}$ is the adsorbent mass ( $\mathrm{g}$ ).

\section{RESULTS AND DISCUSSION}

\section{Characterization Results}

The results obtained by Boehm titration applied to determine the surface functional groups of the adsorbents are given in Table 1. The table contains quantitative values of the carboxylic, phenolic and lactonic groups of the adsorbents in mmol, and as can be seen, the adsorbents have very rich surface groups. When the surface acidic groups of all adsorbents are compared with each other, CCs-SA is the richest adsorbent in total acidic groups. That is, as the concentration of $\mathrm{H}_{2} \mathrm{SO}_{4}$ used in production increases, the total amount of surface functional groups decreases (Table 1). Due to the greater dissociation of acids in dilu- 
te solutions, an increase in the number of active groups bonded on the adsorbents may occur.

When acidic groups are evaluated separately, the richest adsorbent in terms of carboxylic groups is the original CCs. It can be said that some of the carboxyl groups may be degraded during the activation of MK with sulfuric acid at high temperature. On the other hand, CCs are the poorest adsorbent in terms of phenolic and lactonic groups. During the activation with sulfuric acid at high temperature, phenolic and lactonic based new structures are formed on the adsorbents. Besides, depending on the degree of dissociation, large amounts of phenolic and lactonic groups are formed on the CCs-SA 50 surface. As a result, it is understood that during the activation of the original CCs with sulfuric acid, the new adsorbents in which their surface groups are highly variable and rich are formed.

Another remarkable result in this study is that although the starting material (CCs) and activating agent $\left(\mathrm{H}_{2} \mathrm{SO}_{4}\right)$ are the same, only by changing the percentage concentration of the activating agent, adsorbents with quite different surface characteristics can be produced. Therefore, it is possible to produce adsorbents with very different characteristics according to the purpose.

The results found by calculating the $\mathrm{pH}$ and $\mathrm{pH}_{\mathrm{pzc}}$ values of the adsorbents are given in Table 2 and the relevant graphics in Fig. 2. From the table, an increase is observed in the $\mathrm{pH}$ values of the adsorbents obtained with increasing sulfuric acid concentration. This result supports the SAFG analysis results (Table 2). Since the adsorbent with richer surface acidic groups $\left(\mathrm{CCs}-\mathrm{SA}_{50}\right)$ will release more protons in its extraction with water, the $\mathrm{pH}$ value of the relevant adsorbent will be lower. The opposite of this situation is generally observed at $\mathrm{pH}_{\mathrm{pzc}}$ values. Since more base will be required to neutralize the surface of the adsorbent with richer surface acidic groups, the corresponding adsorbent will generally have a higher $\mathrm{pH}_{\mathrm{pzc}}$ value.

Table 1. Quantitative levels of surface acidic functional groups of adsorbents determined by Boehm titration

\begin{tabular}{lcccc}
\hline \multirow{2}{*}{ Adsorbent } & \multicolumn{4}{c}{ Surface acidic groups (mmol/g) } \\
\cline { 2 - 5 } & Total & Carboxylic & Phenolic & Lactonic \\
\hline CCs & 2.43 & 1.75 & 0.35 & 0.32 \\
CCs-SA $_{50}$ & 6.18 & 1.60 & 3.20 & 1.38 \\
CCs-SA $_{75}$ & 5.23 & 1.63 & 2.75 & 0.85 \\
CCs-SA $_{98}$ & 4.15 & 1.05 & 1.75 & 1.35 \\
\hline
\end{tabular}

CCs: Original Corn Cobs

CCs-SA50: The adsorbent obtained by activation of $50 \% \mathrm{H} 2 \mathrm{SO} 4$

CCs-SA75: The adsorbent obtained by activation of $75 \% \mathrm{H} 2 \mathrm{SO} 4$

CCs-SA98: The adsorbent obtained by activation of $98 \% \mathrm{H} 2 \mathrm{SO} 4$
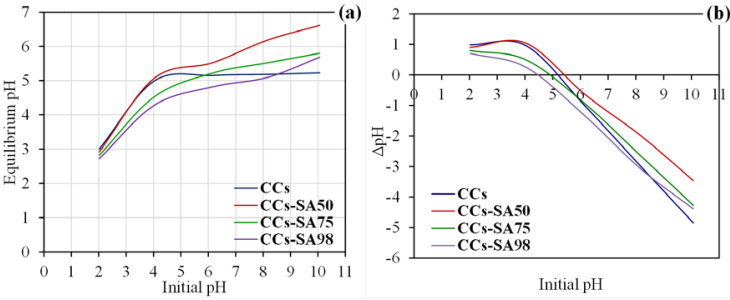

Figure 2. Determination of pHpzc values: (a) Equilibrium $\mathrm{pH}$ vs initial $\mathrm{pH}$ graph, (b) Initial $\mathrm{pH}$ vs $\Delta \mathrm{pH}$ graph

Comparing the differences between the initial and equilibrium $\mathrm{pH}$ values from the graph (Fig. 2(a)), positive differences were observed at low $\mathrm{pH}$ values, while negative differences were generally observed at high $\mathrm{pH}$ values. Since no buffer is used when adjusting the initial $\mathrm{pH}$ of $\mathrm{NaCl}$ solutions, the surface groups of the adsorbents can easily interact with the $\mathrm{H}^{+}$and $\mathrm{OH}^{-}$ions in the solution. While $\mathrm{H}+$ ions pass from solution to adsorbent at low $\mathrm{pH}$ values, $\mathrm{OH}^{-}$ transitions occur at high $\mathrm{pH}$ values.

Table 3 shows the $\mathrm{I}_{2}$ and $\mathrm{MB}$ numbers of the adsorbents. Looking at the table, it is seen that CCs-SA ${ }_{50}$ has the highest number of $\mathrm{I}_{2}$ and $\mathrm{MB}$. Not only porosity but also rich functional groups contribute to the adsorption of large molecule structures. Also, the adsorption of large organic molecules on various adsorbents does not only occur with electrostatic interactions as with small metal ions, besides, but there are also relatively stronger bonds via $\pi-\pi$ interactions. $I_{2}$ is a small molecule, and the high number of $\mathrm{I}_{2}$ indicates the affinity of the adsorbent for small ion or molecules such as metal ions. As seen in this study, $\mathrm{I}_{2}$ numbers are higher than MB numbers. That is, the surface and pore structures of the respective adsorbents may be more favorable for the adsorption of small molecules or ions. However, additional experiments are required to support this result.

The IR spectra taken to determine the types of surface functional groups of adsorbents are shown in Fig.s 3 and 4. A comparison is made by taking spectra both before and after adsorption.

Fig. 3(a) shows the IR spectrum for CCs, the starting material used to produce the adsorbents. A slightly flat peak that appears at $3329 \mathrm{~cm}^{-1}$ is caused by both moisture and hydroxyl $(-\mathrm{OH})$ groups present in the sample. Hydroxyl

Table 2. $\mathrm{pH}$ and $\mathrm{pH}_{\mathrm{pzc}}$ values of the adsorbents

\begin{tabular}{lcc}
\hline Adsorbent & $\mathbf{p H}$ & $\mathbf{p H}_{\mathbf{p z c}}$ \\
\hline $\mathrm{CCs}$ & 5.30 & 5.20 \\
$\mathrm{CCs}^{-S A_{50}}$ & 5.58 & 5.42 \\
$\mathrm{CCs}-\mathrm{SA}_{75}$ & 5.72 & 4.90 \\
$\mathrm{CCs}^{-S_{98}}$ & 6.26 & 4.46 \\
\hline
\end{tabular}


Table 3. $I_{2}$ and MB numbers of the adsorbents (mg/g)

\begin{tabular}{lcc}
\hline Adsorbent & I $_{2}$ number & MB number \\
\hline CCs & 457.7 & 125.7 \\
CCs-SA $_{50}$ & 546.9 & 166.6 \\
CCs-SA $_{75}$ & 504.8 & 132.7 \\
CCs-SA $_{98}$ & 525.0 & 110.3 \\
\hline
\end{tabular}

containing structures; phenols, alcohols, and carboxylic structures. The two peaks at 2920 and $1371 \mathrm{~cm}^{-1}$ are aliphatic $\mathrm{C}-\mathrm{H}$ peaks. The peak appearing at $1729 \mathrm{~cm}^{-1}$ is the $\mathrm{C}=\mathrm{O}$ stretching peak caused by carbonyl groups. The sharp peak at $1033 \mathrm{~cm}^{-1}$ indicates the $\mathrm{C}-\mathrm{C}$ bond, while the peak at 1625 $\mathrm{cm}^{-1}$ is the $\mathrm{C}=\mathrm{C}$ and $\mathrm{C}-\mathrm{O}$ stretching peaks. The peak at 900 $\mathrm{cm}^{-1}$ indicates the $\mathrm{C}-\mathrm{O}-\mathrm{H}$ group.

Fig. 3(b) shows the IR spectrum taken after adsorption of $\mathrm{MB}$ on CCs. It is observed that there is a shift in the transmittance of CCs from $98 \%$ to $80 \%$ after adsorption of $\mathrm{MB}$ (Fig. 3(b)). In other words, a decrease in the transmittance occurred as expected. Also, it is observed that especially the peaks between $1729-900 \mathrm{~cm}^{-1}$ are completely closed and replaced by the peaks seen in the spectrum of pure $\mathrm{MB}$ in Fig. 3(c). This result proves that MB is adsorbed on CCs.

Fig. 4(a) shows the IR spectrum of the CCs-SA ${ }_{50}$ coded adsorbent. The basic peaks to be interpreted here are the peaks at 3360, 1701, 1582, 1368, 1222 and $1039 \mathrm{~cm}^{-1}$ and
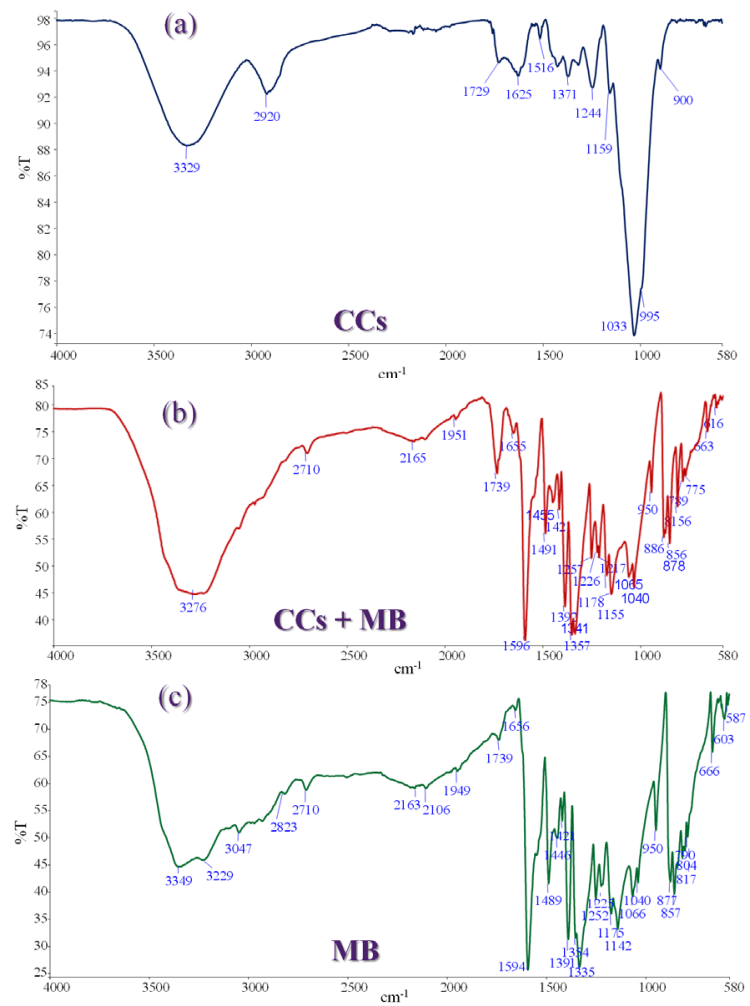

Figure 3. IR spectra for (a) original CCs, (b) MB loaded CCs, and (c) MB belong to the $-\mathrm{OH}, \mathrm{C}=\mathrm{O}, \mathrm{C}=\mathrm{C}, \mathrm{C}-\mathrm{H}, \mathrm{S}=\mathrm{O}$ and $\mathrm{C}-\mathrm{O}$ functional groups, respectively. Comparing with the starting material CCs, it is seen that the surface of the new product $\left(\mathrm{CCs}-\mathrm{SA}_{50}\right)$ obtained by chemical activation has a different chemistry.

The spectrum in Fig. 4(b) was taken after the adsorp-

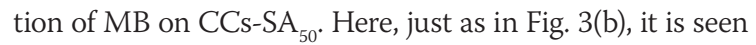
that the spectrum becomes complex and peaks originating from MB appear. In addition, the transmittance value has also changed somewhat here. So as a result, it has been proven that MB molecules are adsorbed on CCs-SA ${ }_{50}$ (Fig. 4 (b)).

\section{Adsorption Performance of the Adsorbents from Aqueous Solution}

\section{Effect of Initial pH}

In this study, as the first parameter, the effect of the initial $\mathrm{pH}$ of the MB solutions on the adsorption efficiency was examined. For this, ten separate MB solutions, each with a concentration of $250 \mathrm{mg} / \mathrm{L}$ and adjusted to $\mathrm{pH}$ values between $1-12$, were prepared. $10 \mathrm{~mL}$ of these solutions and $0.05 \mathrm{~g}$ of adsorbent $(5.0 \mathrm{~g} / \mathrm{L}$ suspension) were mixed and subjected to agitation on a mechanical shaker for 12 hours. At the end of the process, the adsorbent (CCs-SA) and adsorbate molecules (MB) were separated from each other by $0.45 \mu \mathrm{m}$ cellulose nitrate membrane filter by a vacuum filtration device. Absorbance values of unadsorbed $M B$ molecules $\left(C_{e}, \mathrm{mg} / \mathrm{L}\right)$ remaining in the solution were read at $668 \mathrm{~nm}$ in a UV-Vis spectrophotometer and concentrations were calculated with the help of calibration graph plotted with the standard MB solutions. The results were converted to $\mathrm{mg} / \mathrm{g}$ by Eq. 6 .

The initial $\mathrm{pH}$ vs $\mathrm{Q}_{\mathrm{e}}(\mathrm{mg} / \mathrm{g})$ plots were drawn with the data obtained in this parameter (Fig. 5). Fig. 5 illustrated that $\mathrm{MB}$ adsorption efficiency is higher at increasing $\mathrm{pH}$ values. However, there is not a very sharp increase or decrease.

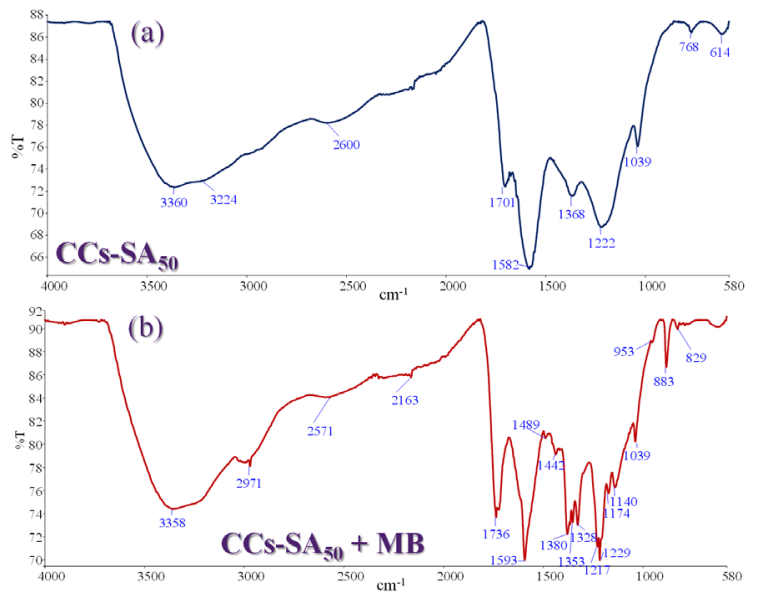

Figure 4. IR spectra for (a) CCS-SA ${ }_{50}$ and (b) MB loaded CCS-SA 


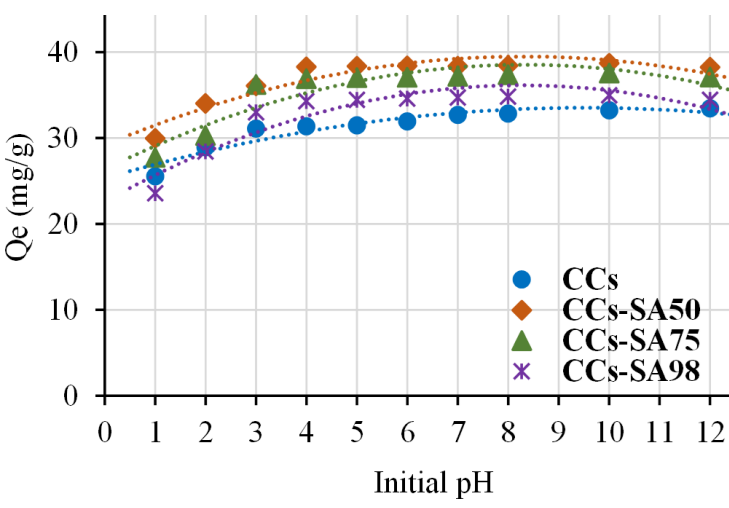

Figure 5. The effect of the initial $\mathrm{pH}$ on removal of $\mathrm{MB}$ from aqueous solution by CCs and CCs-SA (Co: $250 \mathrm{mg} / \mathrm{L}$, adsorbent amount: $5.0 \mathrm{~g} / \mathrm{L}$, agitation time: 4.0 hours, temperature: $25^{\circ} \mathrm{C}$ )

When the performances of the adsorbents are compared with each other, it is seen that the CCs-SA ${ }_{50}$ coded adsorbent obtained with $50 \%$ sulfuric acid has a slightly higher performance. This difference will become more pronounced as the concentration of MB increases.

The MB adsorption performance of CCs used directly after being milled without activating with any agent is lower than the other adsorbents. The most important point to be evaluated here is that adsorbent produced with the lowest concentration of sulfuric acid has shown the highest performance. As it is known, strong acids such as sulfuric acid need an aqueous medium to bring out their acidity strength. If there is enough water (or any solvent in which acid can easily release its protons), acids can easily dissociate by donating protons. Since there is relatively more solvent in 50\% sulfuric acid, sulfuric acid will certainly dissociate more easily. Concentrated acids are therefore considered to be difficult to dissociate.

In the light of the results obtained, it is seen that $\mathrm{pH}$ does not affect much the adsorption efficiency and the optimum $\mathrm{pH}$ range is approximately in the range of 4-10. $\mathrm{pH}$ is the main factor that controls the electrostatic interactions between the adsorbate and the adsorbent. When the solution $\mathrm{pH}$ reaches $\mathrm{pH}_{\mathrm{pzc}}$, the net surface charge of the adsorbent will be zero. The $\mathrm{pH}_{\mathrm{pzc}}$ values of the adsorbents from Table 2 range from 4.46 to 5.42. Although the $\mathrm{MB}$ solution is acidic at these $\mathrm{pH}$ values, the surface of the adsorbents is neutral. The net charge of the adsorbent surface just above the $\mathrm{pH}_{\mathrm{pzc}}$ value is negative, but the MB solution is still acidic. Therefore, at these $\mathrm{pH}$ values, strong electrostatic interactions will occur between $\mathrm{MB}$, a cationic dye, and the adsorbent surface.

Not only electrostatic interactions occur between large organic molecules such as $\mathrm{MB}$ and the respective adsorbent surface, but also strong $\pi-\pi$ interactions between the aromatic rings in the organic molecules and the $\mathrm{C}$ skeleton of the adsorbent. Besides, non-electrostatic partial $\mathrm{H}$ bonds contribute the adsorption. These interactions are much stronger than electrostatic ones and are almost independent of $\mathrm{pH}$.

Since the original $\mathrm{pH}$ values of $\mathrm{MB}$ solutions are between about 4.0-6.0, no $\mathrm{pH}$ adjustment was required in this study.

There are studies in the literature reporting that $\mathrm{pH}$ has little effect on $\mathrm{MB}$ adsorption on various adsorbents.

\section{Effect of Contact Time on MB Adsorption Efficiency and Adsorption Kinetics}

At this stage, the time to reach equilibrium for the adsorption of $\mathrm{MB}$ molecules on the adsorbents was investigated. For this, $5.0 \mathrm{~g} / \mathrm{L}$ adsorbent suspension and 250 $\mathrm{mg} / \mathrm{L} \mathrm{MB}$ solutions were treated for $0-12$ hours. After the solutions taken in different periods were determined by UV-Vis spectrophotometer, the adsorbed amounts $\left(Q_{t}\right)$ per gram adsorbent were calculated. To examine how the adsorption performance has changed during a certain time interval, firstly the $t-Q_{e}$ graph was plotted as seen in Fig. 6 (a). As can be seen from the graph, the adsorption process was completed after 120 minutes for all adsorbents, so equilibrium was almost reached. However, to be guaranteed, the equilibrium time was optimized as 4.0 hours at this stage, and the contact time was applied as 4.0 hours in further applications.

Various kinetic models have been derived to examine how adsorbate molecules/ions behave on adsorbents in terms of the time dependence of adsorption. The three most famous of these models are: (i) pseudo-first-order kinetic model, (ii) pseudo-second-order kinetic model, and (iii) intraparticle diffusion kinetic model [35-37].

The pseudo first-order kinetic model is a model proposed by Lagergren in 1898 [38]. This model is generally applicable for the first minutes of the adsorption event, not for the total adsorption time. That is, it can be applied from the beginning of the adsorption to the period when equilibrium has not yet been reached. This adsorption rate equation is expressed in Eq. (8) below [39]:

$$
\frac{d Q}{d t}=k_{1}\left(Q_{e}-Q_{t}\right)
$$

The linear shape of this equation is given in Eq. 9 below:

$$
\ln \left(Q_{e}-Q_{t}\right)=\ln Q_{e}-k_{1} t
$$

where $\mathrm{Q}_{\mathrm{e}}(\mathrm{mg} / \mathrm{g})$ and $\mathrm{Q}_{\mathrm{t}}(\mathrm{mg} / \mathrm{g})$ indicate the amounts of adsorbate adsorbed on the adsorbent at equilibrium and at time $t$, respectively. $\mathrm{k}_{1}(1 / \mathrm{min})$ is the pseudo-first-order rate constant. If the data fit this model, the $\ln \left(Q_{e}-Q_{t}\right)$ versus t graph (Fig. 6 (b)) is expected to be linear and this 
gives information about whether the kinetic model is suitable for the adsorption data. $\mathrm{Q}_{\mathrm{e}}$ and $\mathrm{k}_{1}$ can be found from the intercept and the slope of the graph, respectively The pseudo-first order kinetic model can be applied more successfully in the case of a relatively high concentration of adsorbate in the solution [40].

Another model used in the analysis of adsorption kinetic data, the pseudo-second-order kinetic model, unlike the pseudo-first-order kinetic model, works in harmony with the rate control step mechanism throughout the entire adsorption period. Moreover, the kinetic results obtained from adsorption studies with relatively low concentrated adsorbate solutions are better fitted to this model. This model is given by the following Eq. (10) [40]:

$$
\frac{d Q_{t}}{d t}=k_{2}\left(Q_{e}-Q_{t}\right)^{2}
$$

When this equation is transformed into its linear form, Eq. 11 below is obtained:

$$
\frac{t}{Q_{t}}=\frac{1}{k_{2} Q_{e}{ }^{2}}-\frac{t}{Q_{e}}
$$

where $\mathrm{k}_{2}$ (g/mg.min) is the second-order rate constant. If a graph to be plotted between $t / Q_{t}$ and $t$ (Fig. 6(c)) is linear and the value of $\mathrm{R}^{2}$ is greater than 0.95 , it can be said that the second-order kinetic model is compatible with the experimental data. $Q_{e}$ and $k_{2}$ can be determined from the slope of the linear graph and the intercept, respectively.

The kinetic data show that the adsorption rate is not compatible with the pseudo-first-order kinetic model but is quite compatible with the pseudo-second-order model. When the experimental $Q_{e}$ values are compared with the theoretical $Q_{e}$ values, it is seen that the experimental data are quite compatible with the second-order rate expression. Additionally, $\mathrm{R}^{2}$ values support this result (Table 4).

The third kinetic model is different from the first two kinetic models. If the diffusion mechanism in porous structures cannot be clearly explained by pseudo-first- and second-order equations, the intraparticle diffusion kinetics can be used. This kinetic model is expressed by the following Eq. (12):

$$
Q_{t}=k_{i d} t^{1 / 2}+C
$$

where $Q_{t}$ is a constant that characterizes the adsorbed quantity $(\mathrm{mg} / \mathrm{g})$ at any time $\mathrm{t}, \mathrm{k}_{\mathrm{id}}\left(\mathrm{mg} / \mathrm{g} \cdot \mathrm{min}^{1 / 2}\right)$ intraparticle diffusion rate constant, and $\mathrm{C}(\mathrm{mg} / \mathrm{g})$ the boundary layer thickness. $\mathrm{k}_{\mathrm{id}}$ and $\mathrm{C}$ can be determined from the slope and intercept of the graph to be plotted between $Q_{t}$ and $t^{1 / 2}$, respectively [41].
The intraparticle diffusion model assumes that the adsorption mechanism generally consists of three steps, and that the adsorption rate is controlled by at least one of these steps: (i) mass transfer from aqueous solution to the external boundary layer of the adsorbent particles as a thin film, (ii) adsorption at sites on the internal or external surface of the adsorbent. Energy at this stage depends on whether the adsorption mechanism is physical or chemical, and this stage is thought to occur quite rapidly, (iii) diffusion towards adsorption sites within the pores of the adsorbent particles [42].

More than one linear correlation can be observed in the graph to be plotted between $Q_{t}$ and $t^{1 / 2}$. The first sharp line observed indicates film diffusion (or boundary layer diffusion) or film adsorption. The second straight line is the section in which the excess adsorbate molecules are adsorbed towards the interior of the pore due to the saturation of the boundary layer, in other words, where intraparticle diffusion is the rate control step. The third part represents the equilibrium state, and in this part, intraparticle diffusion begins to slow down due to the very little adsorbate concentration remaining in the solution. If the second line, the intercept $(\mathrm{C})$ of the line representing intraparticle diffusion, passes through the origin, it is concluded that only intraparticle diffusion is the step controlling the adsorption rate. If it does not pass through the origin, it can be said that the adsorption rate is controlled by more than one mechanism [43].

When looking at the graph for the intraparticle diffusion model in Fig. 6(d), it is seen that two different linear lines are formed. Here, the first line represents intraparticle diffusion. As seen in Fig. 6(d), the first line almost passes through zero. Therefore, it can be said that the rate control step in the adsorption of $\mathrm{MB}$ on the adsorbents is generally controlled by the intraparticle diffusion mechanism. It is also seen from Table 4 that $C$ values are very close to zero.

\section{Concentration Effect on MB Adsorption and Adsorption Isotherms}

In this section, the effect of increasing concentrations of $\mathrm{MB}$ solutions on the adsorption mechanism was investigated by using the fixed mass of four different adsorbents. The relationship between the increasing adsorbate molecule/ion in the solution and the amount of adsorbate adsorbed on per unit quantity of the relevant adsorbent is called "adsorption isotherm". Adsorption isotherms are useful for selecting the most suitable adsorbent in an adsorption process, and also they are very useful in assessing the performance of systems in which adsorption occurs [44]. 

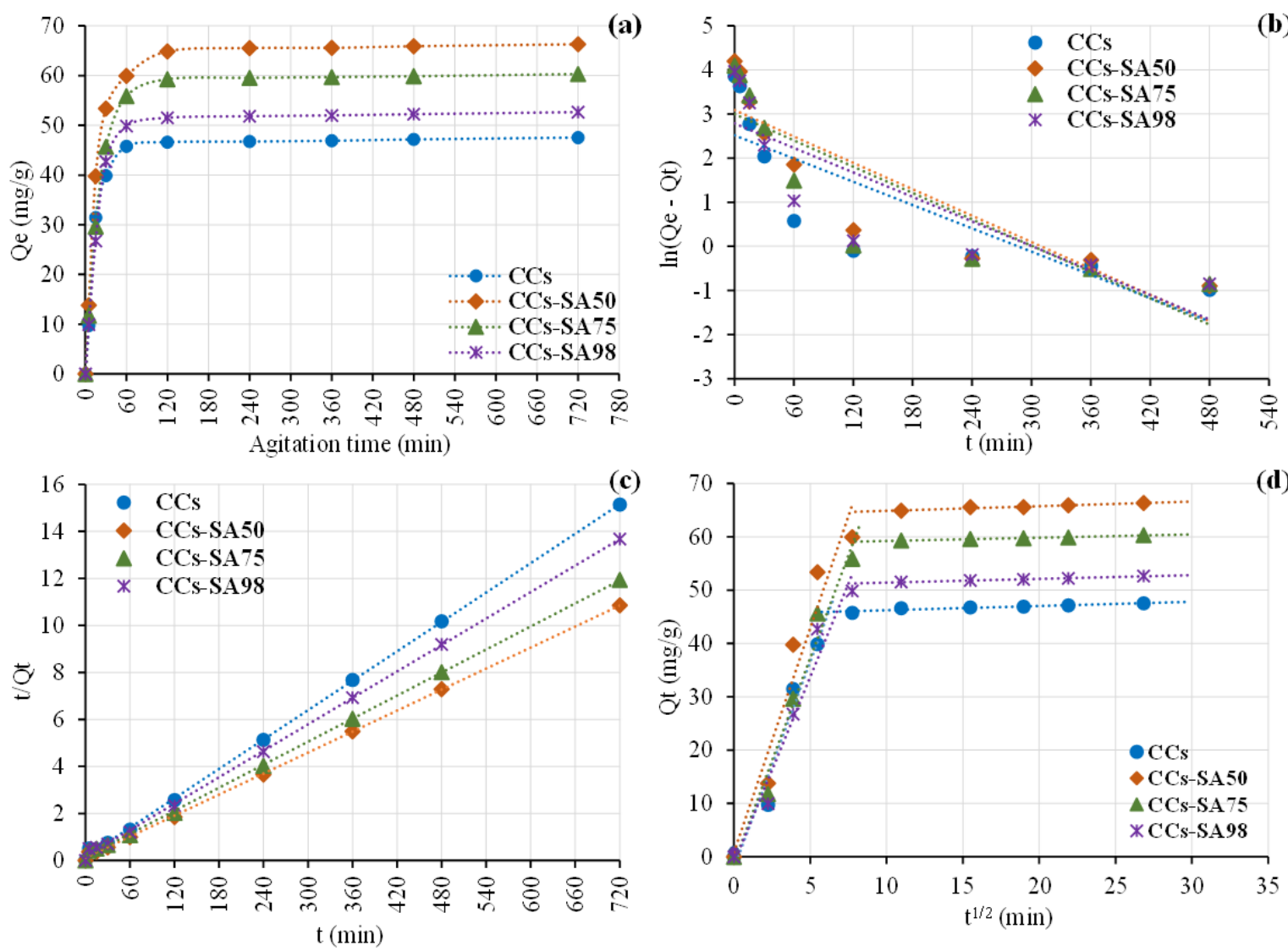

Figure 6. Effect of equilibrium time on the removal of MB from aqueous solution by CCs-SA, and the kinetic models: (a) Effect of time to reach equilibrium, (a) Linear plot of $\ln \left(Q_{e}-Q_{t}\right)$ vs $t$ for pseudo-first-order kinetic model, (b ) linear plot of $t / Q_{t}$ vs $t$ for pseudo-second-order kinetic model, (c) plot of $\mathrm{t}^{1 / 2} \mathrm{vs}$ Qt for intraparticle diffusion kinetic model (pH: 6.0, Co: $500 \mathrm{mg} / \mathrm{L}$, adsorbent amount: $5.0 \mathrm{~g} / \mathrm{L}$, agitation time: $0-12$ hours, temperature: $25^{\circ} \mathrm{C}$ )

$5.0 \mathrm{~g} / \mathrm{L}$ adsorbent suspensions and six different $\mathrm{MB}$ solutions with increasing concentrations between 50 and 1000 $\mathrm{mg} / \mathrm{L}$ were treated for 4.0 hours. Adsorbent particles and adsorbate molecules were separated from each other by filtration, and unadsorbed $\mathrm{MB}$ molecules in the solution were determined by UV-Vis spectrophotometer. The quantities of $\mathrm{MB}$ adsorbed per gram of the adsorbent were calculated from the relevant equaitons.

As can be seen from the $\mathrm{C}_{\mathrm{o}}$ vs $\mathrm{Q}_{\mathrm{e}}$ plot in Fig. 7 (a), the quantity of $\mathrm{MB}$ adsorbed against increasing $\mathrm{MB}$ concentration increases. However, this increase is not linear. The presence of adsorbate molecules increasing against the fixed amount of adsorbent will cause the adsorbent to become saturated after a while and thus the adsorption rate to slow down. Even if the quantity of adsorbate increases after a while, the adsorbent will not be able to adsorb more adsorbate molecules.

It is very useful the adsorption equilibrium isotherms to determine the adsorption capacity of an adsorbent for an adsorbate. In the equilibrium state, there is no concentration change either on the surface of the adsorbent or in the solution. The adsorption capacity of an adsorbent for an ad-

Table 4. Kinetic model constants for MB adsorption from aqueous solution

\begin{tabular}{|c|c|c|c|c|c|c|c|c|c|c|}
\hline \multirow{2}{*}{ Adsorbent } & \multirow{2}{*}{$\begin{array}{l}\mathrm{Q}_{\mathrm{e}}(\text { exp. }) \\
(\mathrm{mg} / \mathrm{g})\end{array}$} & \multicolumn{3}{|c|}{ Pseudo-first-order kinetic } & \multicolumn{3}{|c|}{ Pseudo-second-order kinetic } & \multicolumn{3}{|c|}{ Intraparticle diffusion } \\
\hline & & $\begin{array}{c}\mathrm{Q}_{\mathrm{e}} \text { (theo.) } \\
(\mathrm{mg} / \mathrm{g})\end{array}$ & $\begin{array}{c}\mathbf{k}_{1} \\
\left(\min ^{-1}\right)\end{array}$ & $\mathbf{R}^{2}$ & $\begin{array}{c}\mathrm{Q}_{\mathrm{e}} \text { (theo.) } \\
(\mathrm{mg} / \mathrm{g})\end{array}$ & $\begin{array}{c}\mathbf{k}_{2} \\
\text { (g/mg.min) }\end{array}$ & $\mathbf{R}^{2}$ & $\underset{\left(\mathrm{mg} / \mathrm{g} \cdot \mathrm{min}^{1 / 2}\right)}{\mathbf{k}_{\mathrm{id}}}$ & $\begin{array}{c}\mathrm{C} \\
(\mathrm{mg} / \mathrm{g})\end{array}$ & $\mathbf{R}^{2}$ \\
\hline CCs & 47.53 & 12.38 & $8.79 \times 10^{-3}$ & 0.6848 & 47.96 & $3.02 \times 10^{-2}$ & 0.9995 & 7.74 & -2.15 & 0.9538 \\
\hline CCs-SA ${ }_{50}$ & 66.31 & 21.92 & $9.96 \times 10^{-3}$ & 0.7876 & 67.11 & $1.85 \times 10^{-2}$ & 0.9996 & 8.40 & 0.88 & 0.9420 \\
\hline $\mathrm{CCs} \mathrm{SA}_{75}$ & 60.31 & 20.07 & $9.95 \times 10^{-3}$ & 0.7508 & 61.20 & $1.75 \times 10^{-2}$ & 0.9994 & 7.70 & -1.18 & 0.9770 \\
\hline $\mathrm{CCs}_{-} \mathrm{SA}_{98}$ & 52.65 & 16.26 & $9.26 \times 10^{-3}$ & 0.7277 & 53.33 & $2.12 \times 10^{-2}$ & 0.9994 & 6.98 & -1.14 & 0.9644 \\
\hline
\end{tabular}


sorbate generally includes the relationship of three properties; (i) the concentration of the adsorbate in the fluid phase $\left(C_{\mathrm{e}}\right)$, (ii) the concentration of the adsorbate on the adsorbent $\left(Q_{e}\right)$, and (iii) the temperature of the system $(T)$. If the temperature of the system is kept constant, $C_{e}$ and $Q_{e}$ can be used to create a graph expressing the equilibrium state. This graph is the adsorption isotherm [45].

The graph plotted between the adsorbate concentration $\left(\mathrm{C}_{\mathrm{e}}, \mathrm{mg} / \mathrm{L}\right)$ remaining in the solution after the adsorption process and the quantity of $\mathrm{MB}\left(\mathrm{Q}_{\mathrm{e}}, \mathrm{mg} / \mathrm{g}\right)$ adsorbed on $1 \mathrm{~g}$ of the adsorbent is shown in Fig. 7(b).

Two well-known isotherm models, which provide important information about the adsorption process and the surfaces of adsorbents by establishing a relationship between $\mathrm{C}_{\mathrm{e}}$ and $\mathrm{Q}_{\mathrm{e}}$, stand out today: Langmuir and Freundlich isotherm models.

In the Langmuir adsorption isotherm developed by Irving Langmuir in 1932, the following assumptions were mainly proposed [46]:

- Adsorption of the adsorbate ion or molecules occurs at specific binding sites localized on the surface of the adsorbent.

- All adsorption sites on the surface of the adsorbent have very similar properties to each other.

- At the end of the adsorption process, the surface of the adsorbent is covered with the only monolayer of adsorbed molecules.

- There is no interaction between the adsorbate ion or molecules adsorbed on the adsorbent surface, that is, it is assumed that there is no adsorbate-adsorbate interaction.

The mathematical equation for the curvilinear form of the Langmuir isotherm is as in Eq. 13 below:

$$
Q_{e}=\frac{b C_{e}}{1+b C_{e}}
$$

In Eq. 14, the linearized form of Eq. 13 is given:

$$
\frac{C_{e}}{Q_{e}}=\frac{C_{e}}{Q_{\max }}+\frac{1}{b Q_{\max }}
$$

where $\mathrm{Q}_{\mathrm{e}}$ is the quantity of adsorbate adsorbed by $1 \mathrm{~g}$ adsorbent $(\mathrm{mg} / \mathrm{g}), \mathrm{Q}_{\max }$ is the maximum monolayer adsorption capacity $(\mathrm{mg} / \mathrm{g}), \mathrm{C}_{\mathrm{e}}$ is the concentration of the adsorbate solution after reaching equilibrium ( $\mathrm{mg} / \mathrm{L}$ ), and $b$ represents the Langmuir constant associated with free energy or adsorption enthalpy $(\mathrm{L} / \mathrm{mg})$. The plot of $\mathrm{C}_{\mathrm{e}} / \mathrm{Q}_{\mathrm{e}} \mathrm{vs} \mathrm{C}_{\mathrm{e}}$ is a straight line indicating the suitability of the adsorption to the Langmuir model. $\mathrm{Q}_{\max }$ and $\mathrm{b}$ can be determined from the slope and intercept, respectively.

Another model Freundlich isotherm model, which allows examining the adsorption equilibrium conditions on heterogeneous surfaces with a multi-layer adsorption mechanism, and which was first proposed by German Physical Chemist Herbert Max Finley Freundlich [47].

The curvilinear and linear forms for the Freundlich isotherm model are as Eq.s 15 and 16 below:

$$
\begin{aligned}
& Q e=K_{f} x C e^{1 / n} \\
& \ln Q_{e}=\ln K_{f}+\frac{1}{n} \ln C_{e}
\end{aligned}
$$

where $K_{f}(\mathrm{mg} / \mathrm{g})$ is an empirical parameter associated with the adsorption capacity and $\mathrm{n}$ is the adsorption intensity and indicates the strength of the relationship between adsorbate and adsorbent. High values of $\mathrm{K}_{\mathrm{f}}$ are an indication of how close the affinity of adsorbent and adsorbate to each other. The value of $n$ varies with the heterogeneity of adsorption sites on the adsorbent surface. Also, the value of $\mathrm{n}$ is expected to be between 1 and 10 in terms of suitability of the adsorption process for an adsorbent-adsorbate couple to be selected. The value $1 / \mathrm{n}$ is the heterogeneity factor and generally takes values in the range $0-1$. The more heterogeneous the adsorbent surface is, the closer the $1 / \mathrm{n}$ value becomes zero. The accuracy of this isotherm in heterogeneous adsorption systems is, of course, better than the Langmuir isotherm.

The plot of $\ln C_{e}$ versus $\ln Q_{e}$ is linear, and $K_{f}$ and $1 / n$ can be easily found from the intercept and slope of the line.

Fig.s 7(c) and 7(d) show linear Langmuir and Freundlich isotherm plots for adsorption of $\mathrm{MB}$ on four adsorbents. When the $\mathrm{R}^{2}$ values of the lines are examined first (in Table 5 ), it is seen that the data fit both models with a high correlation. However, when looking at Table $5, \mathrm{R}^{2}$ values for the Langmuir isotherm of other adsorbents except CCs are greater than those for the Freundlich isotherm. In other words, while MB adsorption on CCs is more compatible with the Freundlich model, the Langmuir isotherm model for the other three adsorbents seems more compatible. This result arises from the $\mathrm{R}^{2}$ values obtained from the linear graphs. From the Langmuir linear isotherm, the $\mathrm{Q}_{\max }$ values can be calculated. $\mathrm{Q}_{\max }$ and other constants are given in Table 5. However, an important point here is that these constants change as the quantity of adsorbent changes. As the quantity of adsorbent decreases, the $\mathrm{Q}_{\max }$ values will also increase. The reason for this is discussed in the next parameter (Table 5). Therefore, the quantity of adsorbent used should be considered when comparing the obtained $\mathrm{Q}_{\max }$ values with the literature. 
Looking at the $\mathrm{Q}_{\max }$ values in Table 5, the adsorbent with the code CCs-SA $\mathrm{S}_{50}$ has the highest value as expected. The $Q_{\max }$ value of $1.0 \mathrm{~g} / \mathrm{L}$ adsorbent amount is $295.5 \mathrm{mg} / \mathrm{g}$ and this value is higher than many values obtained from other studies in the literature. A comparison with some studies in the literature on maximum adsorption capacities $\left(\mathrm{Q}_{\max }\right)$ is given in Table 7. (See Conclusion section)

It will be more useful to evaluate the curvilinear isotherm forms to determine which isotherm model is compatible with the adsorption data. New theoretical $Q_{e}$ values are derived by replacing the constants obtained from linear graphs in curvilinear Eq.s (Eq.s 13 and 15) and these values are compared with experimental $Q_{e}$ values on a curvilinear graph. In this respect, when looking at the curvilinear graphs drawn in Fig. 8, it can be interpreted which curve better represents the experimental $Q_{e}$ values (round symbols in black). The first curvilinear graph is for CCs and the experimental points here represent the Freundlich isotherm model best. Because the Freundlich curve follows the experimental points relatively better than the Langmuir curve. Anyway, the $\mathrm{R}^{2}$ value of the related linear graph is slightly higher for the Freundlich isotherm. This height has been proven better here. However, for the other three adsorbents obtained by activation with sulfuric acid, the experimental points represent the best Langmuir isotherm. Both results are understandable. Because, since the original $\mathrm{CCs}$ is a natural structure, there are extremely heteroge- neous formations on its surface. The structure has highly amorphous properties and on its surface, there are functional groups and chemical structures of quite different types and strengths.

\section{Effect of Adsorbent Quantity on MB Adsorption}

In the previous parameter, the changes in the adsorption with increasing $\mathrm{MB}$ concentrations in the fixed adsorbent mass were examined and discussed. Here, the adsorption behavior was observed by increasing the adsorbent mass while the MB concentration was constant, and the data obtained were interpreted. Here, two different $\mathrm{MB}$ concentrations and different adsorbent mass were treated separately, and the maximum capacities were calculated. $10 \mathrm{~mL}$ of $250 \mathrm{mg} / \mathrm{L}$ and $500 \mathrm{mg} / \mathrm{L} \mathrm{MB}$ solutions were treated separately with three different adsorbent quantities of 10, 50 and $100 \mathrm{mg}$ (1.0, 5.0 and $10.0 \mathrm{~g} / \mathrm{L}$ adsorbent suspensions). At the end of the agitation process, after determining the concentrations of unadsorbed $\mathrm{MB}$ in the solution by UV-Vis spectrophotometer, the quantity of $\mathrm{MB}$ adsorbed on the adsorbents with the relevant equations were calculated as both \% and $\mathrm{mg} / \mathrm{g}$, and the graphs were plotted (Fig. 9).

From the Fig. 9, while MB\% adsorption increased with increasing the adsorbent mass, the quantity of adsorbed MB per gram adsorbent decreased. Because, as can be seen from
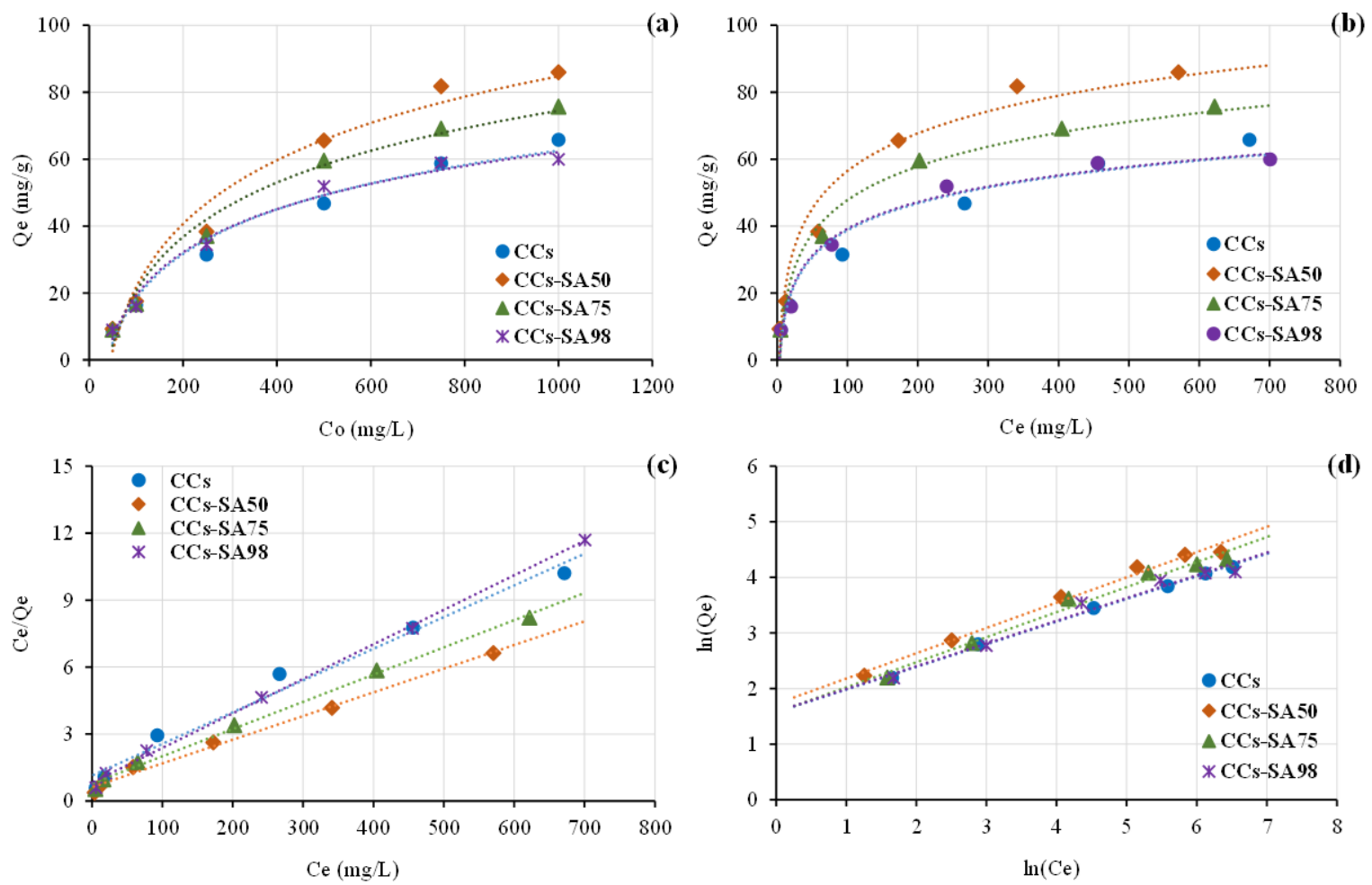

Figure 7. Concentration effect and adsorption isotherms on removal of MB from aqueous solution by CCs-SA: (a) $C_{o} v s Q_{e}$ plot, (b) $C_{e} v s Q_{e}$ plot, (c) Linear Langmuir isotherm plot $\left(\mathrm{C}_{e}\right.$ vs $\mathrm{C}_{e} / \mathrm{Q}_{e}$ plot), (d) Linear Freundlich isotherm plot $\left(\ln \left(\mathrm{C}_{\mathrm{e}}\right) \mathrm{vs} \ln \left(\mathrm{Q}_{\mathrm{e}}\right)\right.$ graph) (pH: 6.0, $\mathrm{C}_{\mathrm{o}}: 50-1000 \mathrm{mg} / \mathrm{L}$, adsorbent quantity: $5.0 \mathrm{~g} / \mathrm{L}$, agitation time: 4.0 hours, temperature: $25^{\circ} \mathrm{C}$ ) 
Table 5. Constants from Langmuir and Freundlich isotherms

\begin{tabular}{|c|c|c|c|c|c|c|c|}
\hline \multirow{2}{*}{ Adsorbent quantity (g/L) } & \multirow{2}{*}{ Adsorbent } & \multicolumn{3}{|c|}{ LANGMUIR } & \multicolumn{3}{|c|}{ FREUNDLICH } \\
\hline & & $\mathrm{Q}_{\max }(\mathrm{mg} / \mathrm{g})$ & $b(\mathrm{~L} / \mathrm{mg})$ & $R^{2}$ & $\mathrm{~K}_{\mathrm{f}}(\mathrm{mg} / \mathrm{g})$ & $n$ & $R^{2}$ \\
\hline \multirow{4}{*}{1.0} & $\mathrm{CCs}$ & 202.5 & $6.46 \times 10^{-3}$ & 0.9698 & 9.63 & 2.291 & 0.9930 \\
\hline & CCs-SA50 & 295.5 & $8.31 \times 10^{-3}$ & 0.9953 & 11.25 & 2.028 & 0.9745 \\
\hline & CCs-SA75 & 215.9 & $1.10 \times 10^{-2}$ & 0.9980 & 12.78 & 2.339 & 0.9596 \\
\hline & CCs-SA98 & 175.7 & $1.39 \times 10^{-2}$ & 0.9995 & 14.09 & 2.605 & 0.9410 \\
\hline \multirow{4}{*}{5.0} & $\mathrm{CCs}$ & 70.4 & $1.24 \times 10^{-2}$ & 0.9787 & 4.83 & 1.574 & 0.9973 \\
\hline & CCs-SA50 & 94.3 & $1.69 \times 10^{-2}$ & 0.9931 & 5.61 & 1.724 & 0.9882 \\
\hline & CCs-SA75 & 82.0 & $1.56 \times 10^{-2}$ & 0.9959 & 4.84 & 1.576 & 0.9811 \\
\hline & CCs-SA98 & 64.7 & $1.86 \times 10^{-2}$ & 0.9979 & 4.87 & 1.583 & 0.9736 \\
\hline \multirow{4}{*}{10.0} & CCs & 55.2 & $1.14 \times 10^{-2}$ & 0.9714 & 2.37 & 0.863 & 0.9984 \\
\hline & CCs-SA50 & 61.5 & $2.00 \times 10^{-2}$ & 0.9955 & 3.19 & 1.159 & 0.9586 \\
\hline & CCs-SA75 & 56.2 & $1.96 \times 10^{-2}$ & 0.9963 & 2.96 & 1.086 & 0.9533 \\
\hline & CCs-SA98 & 51.4 & $2.07 \times 10^{-2}$ & 0.9971 & 2.83 & 1.039 & 0.9422 \\
\hline
\end{tabular}
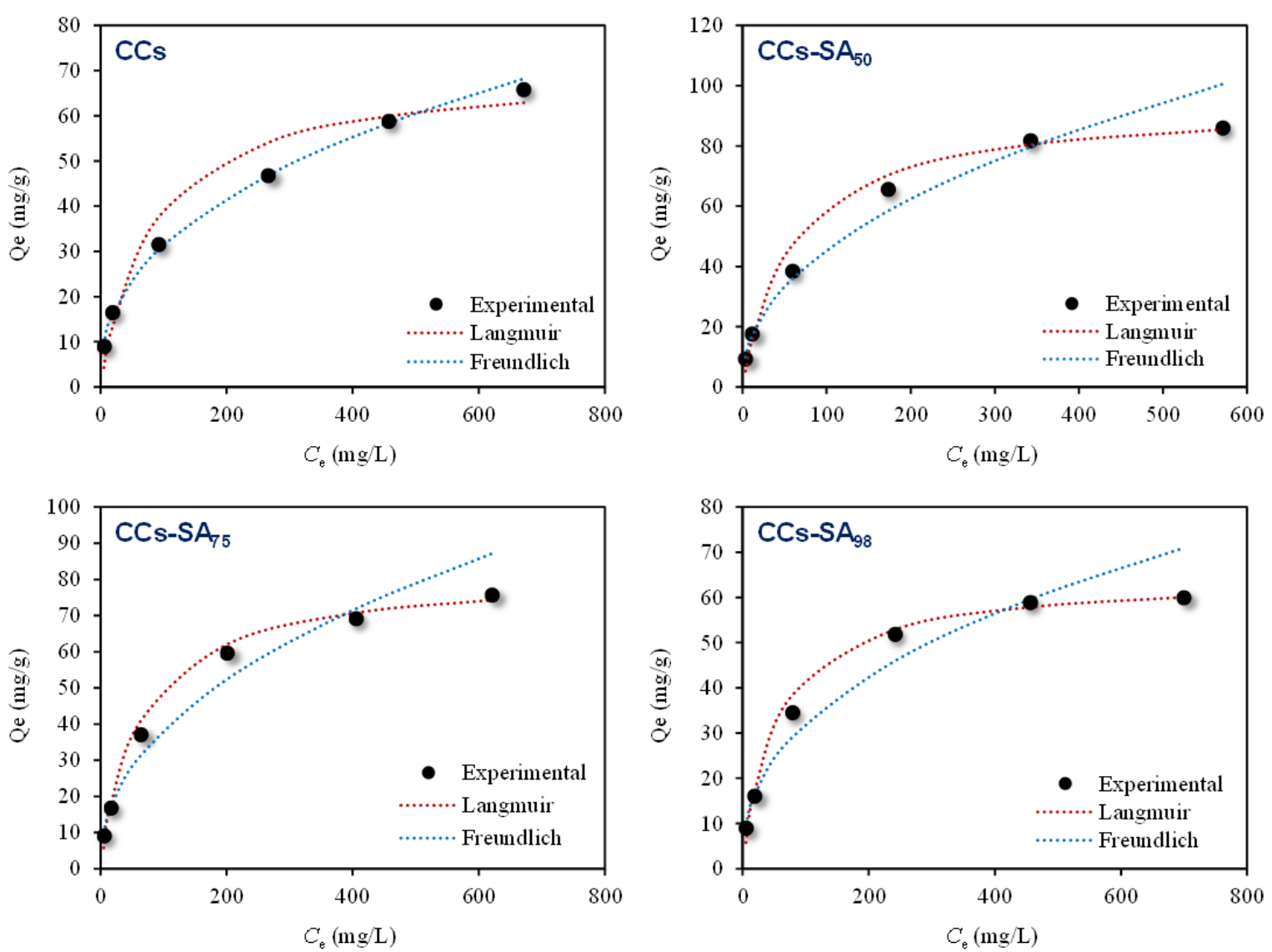

Figure 8. Curvilinear Langmuir and Freundlich isotherms derived for MB adsorption

the figure, the \% increase quantity is not linear. Therefore, when all results obtained are converted into adsorbed quantities per unit adsorbent ( $\mathrm{mg} / \mathrm{g})$, the adsorption efficiency will decrease as expected.
This result can be proved mathematically. If Eq.s (5) and (6) are combined, the following new Eq. (17) is derived. As seen in the equation, the adsorbent mass (m) and Ads.\% are inversely proportional. 


$$
Q e=\frac{A d s . \% \times \mathrm{Co} \times \mathrm{V}}{100 m}
$$

This may be mainly due to two reasons: (i) Increasing the quantity of adsorbent at constant $\mathrm{MB}$ concentration leads to the formation of unsaturated sites on the adsorbent surface. (ii) The adsorption capacity of the adsorbent becomes smaller as the agglomeration of large quantities of adsorbent particles will lead to a decrease in the total surface area. Considering Table 5 given in the previous parameter, as can be seen, the highest capacity value is reached with the lowest adsorbent quantity.

\section{Desorption of MB Molecules Adsorbed on CCs-SA}

Re-use of adsorbents used to remove various types of contaminants from water and wastewater after regeneration is very important for the economics of the process. Therefore, in this parameter, various desorption solutions (1:1 diluted acetone and alcohol solutions, and $0.1 \mathrm{M}$ $\mathrm{HCl}, \mathrm{NaCl}$ and $\mathrm{NaOH}$ solutions) were prepared for the regeneration of loaded adsorbents and their performance was tested.

First, $10 \mathrm{~mL}$ of $100 \mathrm{mg} / \mathrm{L} \mathrm{MB}$ solution was added into a serial tube containing $0.05 \mathrm{~g}$ of adsorbent. After 4.0 hours of agitation under optimum conditions, the adsorbent and adsorbate were separated by filtration. After the loaded adsorbents were thoroughly washed and dried in the air, the desorption solutions shown in Fig 10 were added to them. These desorption solutions were selected based on those used in similar studies in the literature. It can be considered that acetone and alcoholic solvents will perform higher. As can be seen from the column charts in Fig 10, the performance of organic solvents is higher. However, the loaded MB molecules could not be desorbed quantitatively with any desorption solution. There could be several reasons for this. First, MB molecules may be linked by chemical bonds on respective adsorbents. Second, adhesion can be through many mechanisms, not necessarily chemical bonds, but strong and weak. The adsorption mechanisms of dyestuffs can be not only through electrostatic interactions as in metal ions, but also through strong $\pi-\pi$ dispersion interactions between the aromatic rings of the dye molecules and the graphene layers of the adsorbent, and non-electrostatic partial H-bonds [48].

Interactions between the adsorbent and the adsorbate basically occur in two ways; electrostatic and nonelectrostatic. Electrostatic interactions occur where the adsorbate is an electrolyte, that is, it can ionize in the aqueous solution by accepting or donating electrons. These interactions can be attractive or repulsive depending on the solution $\mathrm{pH}$. Non-electrostatic interactions are attractive in all conditions, and mainly include van der Waals forces, hydrophobic interactions, and H-bonding. The factors affecting the adsorption process are the properties of the adsorbent and adsorbate, the solution chemistry, and the adsorption temperature. Compounds containing aromatic groups such as MB are adsorbed on carbon materials mostly with $\pi$-electrons in the aromatic ring [49].

In the next parameter, the physical and chemical mechanism of the adsorption process taking place on the relevant adsorbent is discussed from the thermodynamic data.

\section{Temperature Effect on MB Adsorption and Adsorption Thermodynamics}

The effect of temperature on the adsorption yield is important for the applicability of the process in all seasons. Also, the effect of temperature can give important information about the adsorption mechanism. Thermodynamic evaluations can be made with temperature change. In this regard, $250 \mathrm{mg} / \mathrm{L} \mathrm{MB}$ solutions and $5.0 \mathrm{~g} / \mathrm{L}$ of each adsorbent were treated for 4.0 hours. Then, the MB amount $(\mathrm{mg} / \mathrm{g})$ retained by $1 \mathrm{~g}$ adsorbent was calculated, and temperature change graphs were plotted.

As seen in Fig. 11(a), an increase in temperature reflected positively on the adsorption efficiency. When the temperature increased from $5{ }^{\circ} \mathrm{C}$ to $50^{\circ} \mathrm{C}, \mathrm{MB}$ adsorption increased from $26.4 \mathrm{mg} / \mathrm{g}$ to $39.0 \mathrm{mg} / \mathrm{g}$ (from $52.9 \%$ to $78.0 \%$ ) on CCs, $30.1 \mathrm{mg} / \mathrm{g}$ to $41.5 \mathrm{mg} / \mathrm{g}$ (from $60.2 \%$ to $83.0 \%$ ) on CCs-SA $_{50}, 28.9 \mathrm{mg} / \mathrm{g}$ to $39.2 \mathrm{mg} / \mathrm{g}$ (57.7\% to $\left.78.3 \%\right)$ on CCs$\mathrm{SA}_{75}$ and $28.0 \mathrm{mg} / \mathrm{g}$ to $38.3 \mathrm{mg} / \mathrm{g}(55.9 \%$ to $76 \%$ ) on CCs-SA

The results show that the adsorption behavior of $\mathrm{MB}$ on the relevant adsorbents is endothermic, that is, a process that takes place with higher efficiency by accepting the temperature of the environment. The positive effect of temperature increase on the efficiency of adsorption can be attributed to reasons such as the increase in the interaction between the adsorbent and the adsorbate more, the passive sites becoming more active, and the expansion of the pore structures of the adsorbent, and the more effective role of intra-particle diffusion.

Adsorption thermodynamics were also examined from the temperature change data obtained at this stage. Thermodynamics determines the internal energy, enthalpy, entropy, and free energy values of the system during a physical or chemical transformation and examines their dependence on the reaction conditions [50]. The thermodynamic parameters $\Delta \mathrm{G}, \Delta \mathrm{S}$ and $\Delta \mathrm{H}$ can be found from the following equations:

$$
\begin{aligned}
& \Delta G=\Delta H-T \Delta S \\
& K_{d}=C_{a} / C_{e}
\end{aligned}
$$



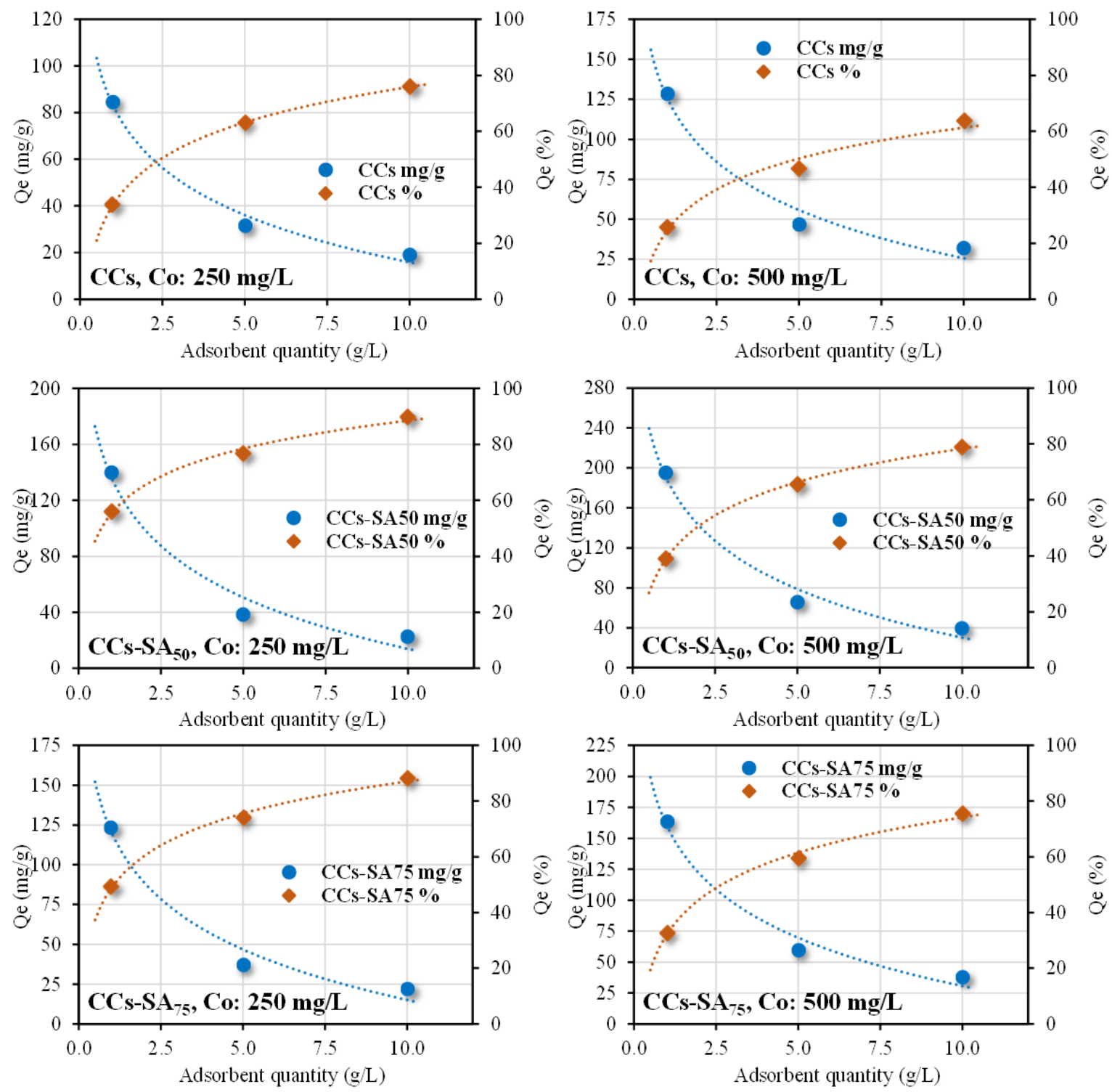

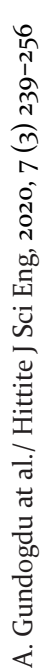
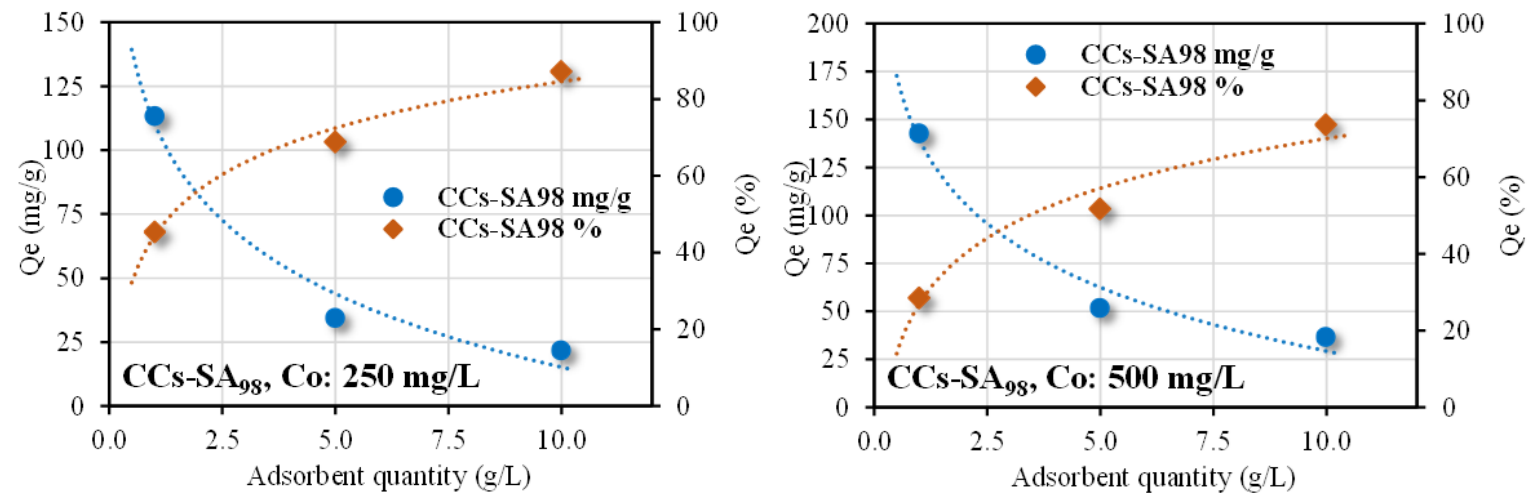

Figure 9. The effect of the adsorbent quantity on the removal of $\mathrm{MB}$ from the aqueous solution by CCs-SA (pH: $6.0, \mathrm{C}: 250$ and $500 \mathrm{mg} / \mathrm{L}$, adsorbent quantity: $1.0,5.0$ and $10.0 \mathrm{~g} / \mathrm{L}$, agitation time: 4.0 hours, temperature: $25^{\circ} \mathrm{C}$ )

$$
\begin{aligned}
& \Delta G=-R T \ln K_{d} \\
& \ln K_{d}=\frac{\Delta S}{R}-\frac{\Delta H}{R}
\end{aligned}
$$

$\Delta$ G: Gibbs free energy change $(\mathrm{kJ} / \mathrm{mol})$

$\Delta \mathrm{H}$ : Enthalpy change $(\mathrm{kJ} / \mathrm{mol})$

$\Delta \mathrm{S}$ : Entropy change (kJ/mol.K)

T: Absolute temperature (K) 

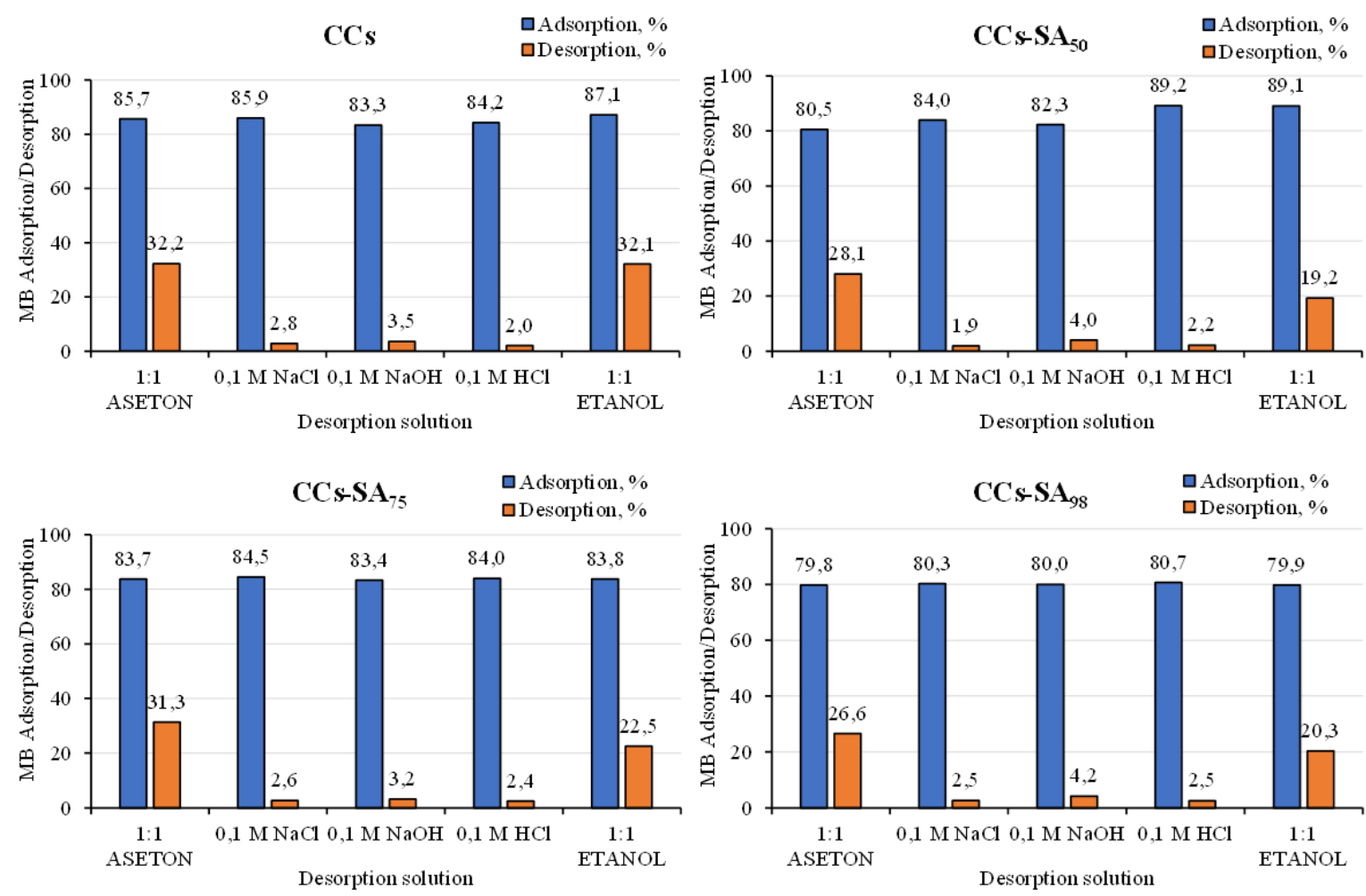

Figure 10. Desorption of MB molecules adsorbed on the adsorbents $\left(C_{\mathrm{o}}: 100 \mathrm{mg} / \mathrm{L}\right)$
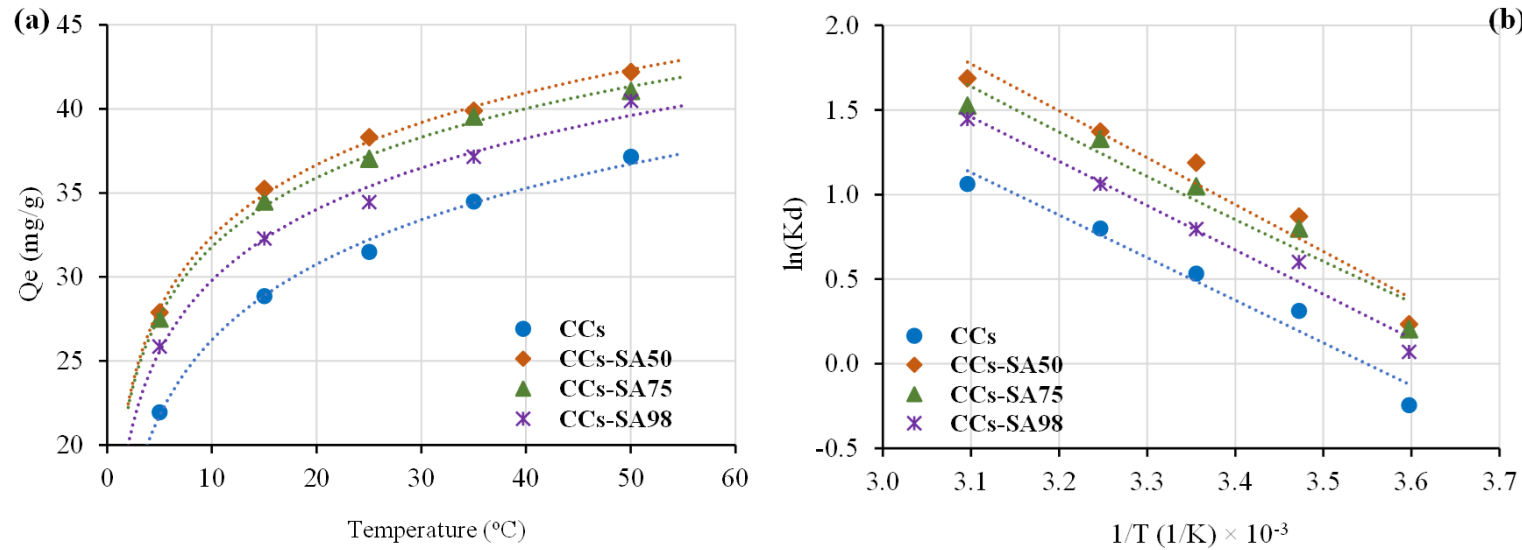

(b)

Figure 11. (a) Effect of medium temperature on removal of $\mathrm{MB}$ from aqueous solution by CCs-SA, (b) $1 / \mathrm{T}-\ln \left(\mathrm{K}_{\mathrm{d}}\right)$ graph for thermodynamic data (pH: 6.0, $\mathrm{C}_{\mathrm{o}}: 250 \mathrm{mg} / \mathrm{L}$, adsorbent quantity: $5.0 \mathrm{~g} / \mathrm{L}$, agitation time: 4.0 hours, temperature: $5-50^{\circ} \mathrm{C}$ )

R: Universal gas constant (J/mol.K)

$\mathrm{K}_{\mathrm{d}}$ : Adsorption equilibrium constant

$\mathrm{C}_{\mathrm{a}}$ : The concentration of adsorbate retained in the unit mass of the adsorbent $(\mathrm{mg} / \mathrm{L})$

$\mathrm{C}_{\mathrm{e}}$ : The concentration of adsorbate left in the solution after adsorption $(\mathrm{mg} / \mathrm{L})$

First, the equilibrium constant $K_{d}$ is calculated from Eq. 19. A graph to be plotted between $\ln \left(K_{d}\right)$ and 1/T in Eq. 21 is expected to be linear as in Fig. 11(b). While the slope of this graph gives $\Delta \mathrm{H}, \Delta \mathrm{S}$ can be found from the intercept.

The data obtained from thermodynamic calculations are given in Table 6. With increasing temperature, $\Delta \mathrm{G}$ valu- es become increasingly negative. A negative value of $\Delta \mathrm{G}$ indicates that adsorption occurs spontaneously. The enthalpy value of physical adsorption is generally not greater than 4 $\mathrm{kJ} / \mathrm{mol}$, but not less than $20 \mathrm{~kJ} / \mathrm{mol}$ for chemical adsorption [51]. Therefore, when looking at the $\Delta \mathrm{H}$ values obtained from this study in Table 6, it is seen that all of them are slightly higher than $20 \mathrm{~kJ} / \mathrm{mol}$. In other words, it can be said that the adsorption process proceeds by chemical means. In the previous parameter, it was discussed that MB molecules retained on the adsorbents could not be quantitatively desorbed. The results obtained from the thermodynamic data also confirm this result due to the possibility of the process being chemical. 
Table 6. The effect of ambient temperature on the removal of $\mathrm{MB}$ from aqueous solution by CCs-SA: Thermodynamic data

\begin{tabular}{|c|c|c|c|c|c|}
\hline Adsorbent & $T\left({ }^{\circ} \mathrm{C}\right)$ & $\mathrm{K}_{\mathrm{d}}$ & $\begin{array}{c}\Delta \mathrm{G} \\
(\mathrm{kJ} / \mathrm{mol})\end{array}$ & $\begin{array}{c}\Delta S \\
(\mathrm{~J} / \mathrm{mol} . \mathrm{K})\end{array}$ & $\begin{array}{c}\Delta \mathrm{H} \\
(\mathrm{kJ} / \mathrm{mol})\end{array}$ \\
\hline \multirow{5}{*}{ CCs } & 5 & 0.78 & 0.57 & \multirow{5}{*}{74.26} & \multirow{5}{*}{20.92} \\
\hline & 15 & 1.37 & -0.75 & & \\
\hline & 25 & 1.70 & -1.32 & & \\
\hline & 35 & 2.22 & -2.05 & & \\
\hline & 50 & 2.89 & -2.85 & & \\
\hline \multirow{5}{*}{ CCs-SA ${ }_{50}$} & 5 & 1.31 & -0.62 & \multirow{5}{*}{82.64} & \multirow{5}{*}{22.00} \\
\hline & 15 & 2.36 & -2.06 & & \\
\hline & 25 & 3.28 & -2.94 & & \\
\hline & 35 & 3.90 & -3.49 & & \\
\hline & 50 & 5.20 & -4.43 & & \\
\hline \multirow{5}{*}{ CCs-SA ${ }_{75}$} & 5 & 1.23 & -0.47 & \multirow{5}{*}{79.76} & \multirow{5}{*}{21.35} \\
\hline & 15 & 2.22 & -1.91 & & \\
\hline & 25 & 2.85 & -2.60 & & \\
\hline & 35 & 3.78 & -3.40 & & \\
\hline & 50 & 4.60 & -4.10 & & \\
\hline \multirow{5}{*}{$\mathrm{CCs}-\mathrm{SA}_{98}$} & 5 & 1.07 & -0.16 & \multirow{5}{*}{79.64} & \multirow{5}{*}{21.78} \\
\hline & 15 & 1.82 & -1.44 & & \\
\hline & 25 & 2.21 & -1.97 & & \\
\hline & 35 & 2.89 & -2.72 & & \\
\hline & 50 & 4.24 & -3.88 & & \\
\hline
\end{tabular}

Positive $\Delta S$ values increase the probability of random formation of the adsorption equilibrium occurring at the solid-liquid interface during adsorption. In other words, it indicates an increase in the amount of energy that cannot be used, that is, an increase in the disorder of the system.

\section{CONCLUSION}

In this study, three new adsorbents were produced by chemical activation using different concentrations of sul- furic acid from corn cobs (CCs). Based on the results obtained from the characterization and adsorption studies, the following results were obtained:

- The adsorbent with the richest surface acidic functio-

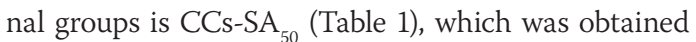
by activating with the lowest concentration of sulfuric acid (50\%)

- When the $\mathrm{I}_{2}$ and $\mathrm{MB}$ numbers of the adsorbents were evaluated, it was found that the adsorbent with the code CCs-SA 50 had the highest values.

- It has been observed that MB molecules are adsorbed on all adsorbents with high efficiency over a wide initial $\mathrm{pH}$ range, and it has been observed that a precise $\mathrm{pH}$ adjustment is not required before adsorption tests. Since the original $\mathrm{pH}$ values of the $\mathrm{MB}$ solutions are around 6 , there is no need to make any $\mathrm{pH}$ adjustment before the operations.

- When Langmuir adsorption capacities of adsorbents are compared, the $\mathrm{MB}$ capacity of the adsorbent with the code CCs-SA $\mathrm{S}_{50}$ is the highest. This result proves that the adsorbent produced by dilute sulfuric acid activation has a higher capacity.

- Table 7 presents a comparison of the capacity value obtained from this study with the literature. As can be seen from the table, the capacity value obtained from this study is higher than many studies in the literature. Therefore, it has been proven that especially the adsorbent with the CCs-SA ${ }_{50}$ code can be used effectively in removing dyes from contaminated water.

- It has been determined that the increase of the medium temperature has a positive effect on $\mathrm{MB}$ adsorption, ad-

Table 7. Comparison of the MB adsorption capacities with the literature

\begin{tabular}{|c|c|c|c|c|c|}
\hline$Q_{\max }(\mathrm{mg} / \mathrm{g})$ & $Q \max (m g / g)$ & Adsorbent mass (g/L) & Solution pH & Ads. Temp. (oC) & Ref. \\
\hline Sunflower oil cake & 16.43 & 2.0 & 6.0 & 25 & {$[52]$} \\
\hline Posidonia oceanica (L.) dead leaves & 270.3 & 5.0 & 6.5 & 30 & [53] \\
\hline $\mathrm{CuO}$ loaded coconut shell $\mathrm{AC}^{*}$ & 331.5 & 3.0 & 9.0 & 45 & {$[54]$} \\
\hline Surfactant-modified AC & 232.5 & 0.15 & 5.0 & 25 & {$[55]$} \\
\hline Corn cob activated carbon & 37.45 & 0.5 & 6.0 & 35 & {$[56]$} \\
\hline Jute fiber carbon & 225.64 & 1.5 & 4.0 & 28 & {$[57]$} \\
\hline Graphene & 153.85 & 0.5 & $3.0-10.0$ & 20 & {$[58]$} \\
\hline Garlic peel & 82.64 & 3.0 & $6.0-10.0$ & 30 & [59] \\
\hline Cedar sawdust & 111.97 & 5.0 & 7.0 & 20 & [60] \\
\hline Activated corn cobs & 295.5 & 1.0 & 6.0 & 25 & This study \\
\hline
\end{tabular}


sorption is a spontaneous process, and since $\Delta H$ values are greater than $20 \mathrm{~kJ} / \mathrm{mol}$, MB adsorption on the adsorbents mainly proceeds chemically.

In conclusion, thanks to this study, both the waste materials have been regained an economic value and the possible damages of these wastes to the environment have been prevented. Besides, it will be possible to eliminate other pollution with the adsorbents produced from these wastes.

\section{References}

1. Carneiro PA, Umbuzeiro GA, Oliveira DP, Zanoni MVB Assessment of water contamination caused by a mutagenic textile effluent/dyehouse effluent bearing disperse dyes. Journal of Hazardous Materials 174 (2010) 694-699.

2. Zollinger H. Color Chemistry - Synthesis, properties and applications of organic dyes and pigments. V.C.H. Publishers, New York, 1991.

3. McKay G, Otterburn MS, Sweeney AG. The removal of colour from effluent using various adsorbents - III. Silica: Rate process. Water Research 14(1) (1980) 15-20.

4. Garg VK, Amita M, Kumar R, Gupta R. Basic dye (methylene blue) removal from simulated wastewater by adsorption using Indian Rosewood sawdust: a timber industry waste. Dyes Pigments 63(3) (2004) 243-250

5. Ramakrishna KR, Viraraghavan T. Dye removal using low cost adsorbents. Water Science \& Technology 36 (1997) 189-196.

6. Waranusantigul P, Pokethitiyook P, Kruatrachue M, Upatham ES. Kinetics of basic dye (methylene blue) biosorption by giant duckweed (Spirodela polyrrhiza). Environmental Pollution 125 (2003) 385-392.

7. Pilatin S. Kunduhoğlu B. Biyoadsorbsiyon ve kat1-faz fermantasyonu ile boya gideriminde tarımsal atıkların kullanım potansiyeli. Biyoloji Bilimleri Araştırma Dergisi 11(2) (2018) 30-34

8. Korkut Z. Removal of some heavy metals from aqueous solutions by modified carrot peel. Istanbul Technical University, Graduate Institute of Natural and Applied Sciences, Master Thesis, Istanbul, 2014.

9. Bayraktar AK. Removal of lead(II), nickel(II), methylene blue and Rhodamine B by natural and activated alder sawdust (In Turkish) Karadeniz Technical University, Graduate Institute of Natural and Applied Sciences, Chemistry MSc, Master Thesis, Trabzon, 2012.

10. Pellera F-M, Giannis A, Kalderis D. Anastasiadou K, Stegmann R, Wang J-Y, Gidarakos E. Adsorption of $\mathrm{Cu}(\mathrm{II})$ ions from aqueous solutions on biochars prepared from agricultural by-products. Journal of Environmental Management 96 (2012) 35-42.

11. Mahmoodi NM, Taghizadeh M, Taghizadeh A. Mesoporous activated carbons of low-cost agricultural bio-wastes with high adsorption capacity: Preparation and artificial neural network modeling of dye removal from single and multicomponent (binary and ternary) systems. Journal of Molecular Liquits 269 (2018) $217-$ 228.

12. Karthika M, Vasuki M. Adsorption of alizarine red-s dye from aqueous solution by sago waste: Resolution of isotherm, kinetics and thermodynamics. Materials Today: Proceedings 14 (2019) 358-367.

13. Tran TH, Le AH, Pham TH, Nguyen DT, Chang SW, Chung WJ, Nguyen DD. Adsorption isotherms and kinetic modeling of methylene blue dye onto carbonaceous hydrochar adsorbent derived from coffee husk waste. Science of the Total Environment 725 (2020) 138325

14. Garg D, Kumar S, Sharma K, Majumder CB. Application of waste peanut shells to form activated carbon and its utilization for the removal of Acid Yellow 36 from wastewater. Groundwater for Sustainable Development 8 (2019) 512-519.

15. Yusmaniar Y, Erdawati E, Ghifari YF, Ubit DP. Synthesis of mesopore silica composite from rice husk with activated carbon from coconut shell as absorbent methyl orange color adsorbent. IOP Conference Series: Materials Science and Engineering 830 (2020) 032078 .

16. Imamoglu M, Ozturk A, Aydın Ş, Manzak A, Gündoğdu A, Duran C. Adsorption of $\mathrm{Cu}(\mathrm{II})$ ions from aqueous solution by hazelnut husk activated carbon prepared with potassium acetate. Journal of Dispersion Science and Technology 39(8) 2018 1144-1148.

17. Gundogdu A, Duran C, Senturk HB, Soylak M, Imamoglu M, Onal Y. Physicochemical characteristics of a novel activated carbon produced from tea industry waste. Journal of Analytical Applied. Pyrolisis 104 (2013) 249-259.

18. URL-1. Bitkisel Üretim Genel Müdürlüğü Tarım Havzaları Daire Başkanlığı, Mısır Bülteni (Kasım 2019), https://www.tarimorman. gov.tr/BUGEM/Belgeler/M\%C4\%B0LL\%C4\%B0\%20TARIM/ MISIR\%20KASIM\%20B\%C3\%9CLTEN\%C4\%B0.pdf. Retrieved August 15, 2020.

19. Vadivelan V, Kumar KV. Equilibrium, kinetics, mechanism, and process design for the sorption of methylene blue onto rice husk. Journal of Colloid and Interface Science 286 (2005) 90-100.

20. Vargas AMM, Cazetta AL, Kunita MH, Silva TL, Almeida VC. Adsorption of methylene blue on activated carbon produced from flamboyant pods (Delonix regia): Study of adsorption isotherms and kinetic models. Chemical Engineering Journal 168(2) (2011) 722-730.

21. Theydan SK, Ahmed MJ. Adsorption of methylene blue onto biomass-based activated carbon by $\mathrm{FeCl} 3$ activation: Equilibrium, kinetics, and thermodynamic studies. Journal of Analytical and Applied Pyrolisis 97 (2012) 116-122.

22. Raposo F, De La Rubia MA, Borja R. Methylene blue number as useful indicator to evaluate the adsorptive capacity of granular activated carbon in batch mode: Influence of adsorbate/adsorbent mass ratio and particle size. Journal of Hazardous Materials 165 (2009) 291-299.

23. Söyleyici Cergel M, Demir E, Atay F. The effect of the structural, optical, and surface properties of anatase-TiO2 film on photocatalytic degradation of methylene blue organic contaminant. Ionics 25 (2019) 4481-4492.

24. Pathania D, Sharma S, Singh P. Removal of methylene blue by adsorption onto activated carbon developed from Ficus carica bast, Arabian Journal of Chemistry 10(1) (2017) 1445-1451.

25. Jawad AH, Mohammed SA, Mastuli MS, Abdullah MF. Carbonization of corn (Zea mays) cob agricultural residue by onestep activation with sulfuric acid for methylene blue adsorption. Desalination and Water Treatment 118 (2018) 342-351.

26. URL-2. Methylene blue, https://en.wikipedia.org/wiki/Methylene_ blue. Retrieved August 15, 2020.

27. Duran C, Ozdes D, Gundogdu A, Imamoglu M, Senturk HB. Tea industry waste activated carbon, as a novel adsorbent, for separation, preconcentration and speciation of chromium. Analytica Chimica Acta 688(1) (2011) 75-83.

28. Boehm HP. Chemical identification of surface groups. Advances in Catalysis 16 (1966) 179-274.

29. Muthmann J, Blaker C, Pase C, Luckas M, Schledorn C, Bathen D. Characterization of structural and chemical modifications 
during the steam activation of activated carbons. Microporous and Mesoporous Materials 309 (2020) 110549.

30. Girods P, Dufour A, Fierro V, Rogaume Y, Rogaume C, Zoulalian A, Celzard A. Activated carbons prepared from wood particleboard wastes: Characterisation and phenol adsorption capacities. Journal of Hazardous Materials 166 (2009) 491-501.

31. Cimirro NFGM, Lima EC, Cunha MR, Dias SLP, Thue PS, Mazzocato AC, Dotto GL, Gelesky MA, Pavan FA. Removal of pharmaceutical compounds from aqueous solution by novel activated carbon synthesized from lovegrass (Poaceae). Environmental Science and Pollution Research 27 (2020) 21442-21454.

32. Saha A, Basak BB, Ponnuchamy M. Performance of activated carbon derived from Cymbopogon winterianus distillation waste for scavenging of aqueous toxic anionic dye Congo red: Comparison with commercial activated carbon. Separation Science and Technology 55(11) (2020) 1970-1983.

33. Sun K, Jiang JC. Preparation and characterization of activated carbon from rubber-seed shell by physical activation with steam. Biomass \& Bioenergy 34 (2010) 539-544.

34. ASTM D4607-94(1999). Standard test method for determination of iodine number of activated carbon, annual book of ASTM standards, 2006, vol.15.01.

35. Moussout H, Ahlafi H, Aazza M, Maghat H. Critical of linear and nonlinear equations of pseudo-first order and pseudo-second order kinetic models. Karbala International Journal of Modern Science 4(2) 2018, 244-254.

36. Simonin J-P. On the comparison of pseudo-first order and pseudosecond order rate laws in the modeling of adsorption kinetics. Chemical Engineering Journal 300(15) (2016) 254-263.

37. Wu F-C, Tseng R-L, Juang R-S. Initial behavior of intraparticle diffusion model used in the description of adsorption kinetics. Chemical Engineering Journal 153(1-3) (2009) 1-8.

38. Lagergren S. About the theory of so-called adsorption of soluble substance. Kungliga Svenska Veterskopsakademiens Handlinga 24 (1898) 1-39.

39. Kumar KV. Linear and non-linear regression analysis for the sorption kinetics of methylene blue onto activated carbon. Journal of Hazardous Materials 137(3) (2006) 1538-1544.

40. Ray SS, Gusain R, Kumar N. Carbon nanomaterial-based adsorbents for water purification, fundamentals and applications micro and nano technologies: Chapter five - Adsorption equilibrium isotherms, kinetics and thermodynamics. 2020, Pages 101-118, Elsevier Inc.

41. Weber Jr WJ, Morris JC. Kinetics of adsorption on carbon from solution. Journal of the Sanitary Engineering Division 89 (1963) 31-59.

42. Cheung WH, Szeto YS, McKay G. Intraparticle diffusion processes during acid dye adsorption onto chitosan. Bioresource Technology 98(15) (2007) 2897-2904.

43. Kavitha D, Namasivayam C. Capacity of activated carbon in the removal of acid brilliant blue: determination of equilibrium and kinetic model parameters. Chemical Engineering Journal 139 (2008) 453-461.

44. Doran PM. Bioprocess engineering principles (Second Edition), Chapter 11 - Unit operations. 2013, Pages 445-595, Elsevier Inc.

45. Qada ENE, Allen SJ, Walker GM. Adsorption of methylene blue onto activated carbon produced from steam activated bituminous coal: A study of equilibrium adsorption isotherm. Chemical Engineering Journal 124 (2006) 103-110.

46. Langmuir I. The adsorption of gases on plane surfaces of glass, mica and platinum. Journal of American Chemical Society 40 (1918) 1361-1403.

47. Freundlich HMF. Über die Adsorption in lösungen, zeitschrift für physikalische chemie. 57 (1906) 385-470

48. Bhomick PC, Supong A, Baruah M, Pongener C, Gogoil C, Sinha D. Alizarin red $\mathrm{S}$ adsorption onto biomass based activated carbon: Optimization of adsorption process parameters using Taguchi experimental design. International Journal of Environmental Science and Technology 17 (2020) 1137-1148.

49. Moreno-Castilla C. Adsorption of organic molecules from aqueous solutions on carbon materials. Carbon 42 (2004) 83-94.

50. Gundogdu A, Duran C, Senturk HB, Soylak M, Ozdes D, Serencam $\mathrm{H}$, Imamoglu M. Adsorption of phenol from aqueous solution on a low-cost activated carbon produced from tea industry waste: Equilibrium, kinetic, and thermodynamic study. Journal of Chemical and Engineering Data 57(10) (2012) 733-2743.

51. Khormaei M, Nasernejad B, Edrisi M, Eslamzadeh T. Copper biosorption from aqueous solutions by sour orange residue. Journal of Hazardous Materials 149 (2007) 269-274

52. Karagoz S, Tay T, Ucar S, Erdem M. Activated carbons from waste biomass by sulfuric acid activation and their use on methylene blue adsorption. Bioresource Technology 99 (2008) 6214-6222.

53. Dural MU, Cavas L, Papageorgiou SK, Katsaros FK. Methylene blue adsorption on activated carbon prepared from Posidonia oceanica (L.) dead leaves: Kinetics and equilibrium studies. Chemical and Engineering Journal 168 (2011) 77-85.

54. Prajapati AK, Mondal MK. Comprehensive kinetic and mass transfer modeling for methylene blue dye adsorption onto $\mathrm{CuO}$ nanoparticles loaded on nanoporous activated carbon prepared from waste coconut shell. Journal of Molecular Liquits 307 (2020) 112949.

55. Kuang Y, Zhang X, Zhou S. Adsorption of methylene blue in water onto activated carbon by surfactant modification. Water $12(2)$ (2020) 587.

56. Aljeboree AM, Hussein FH, Alkaim AF. Removal of textile dye (methylene blue $\mathrm{mb}$ ) from aqueous solution by activated carbon as a model (corn-cob source waste of plant): As a model of environmental enhancement. Plant Archives 19(2) (2019) 906-909.

57. Senthilkumaar S, Varadarajan PR, Porkodi K, Subbhuraam CV. Adsorption of methylene blue onto jute fiber carbon: kinetics and equilibrium studies. Journal of Colloid and Interface Science 284(1) (2005) 78-82.

58. Liu T, Li Y, Du Q, Sun J, Jiao Y, Yang G, Wang Z, Xia Y, Zhang W, Wang K, Zhu H, Wu D. Adsorption of methylene blue from aqueous solution by graphene. Colloids and Surfaces B: Biointerfaces 90 (2012) 197-203.

59. Hameed BH, Ahmad AA. Batch adsorption of methylene blue from aqueous solution by garlic peel, an agricultural waste biomass. Journal of Hazardous Materials 164 (2009) 870-875.

60. Hamdaoui O. Batch study of liquid-phase adsorption of methylene blue using cedar sawdust and crushed brick. Journal of Hazardous Materials 135(1-3) (2006) 264-273. 